\title{
WestVirginiaUniversity
}

THE RESEARCH REPOSITORY @ WVU

Graduate Theses, Dissertations, and Problem Reports

2014

\section{The use of technology to display student artwork online}

\author{
Elissa Dray \\ West Virginia University
}

Follow this and additional works at: https://researchrepository.wvu.edu/etd

\section{Recommended Citation}

Dray, Elissa, "The use of technology to display student artwork online" (2014). Graduate Theses, Dissertations, and Problem Reports. 590.

https://researchrepository.wvu.edu/etd/590

This Thesis is protected by copyright and/or related rights. It has been brought to you by the The Research Repository @ WVU with permission from the rights-holder(s). You are free to use this Thesis in any way that is permitted by the copyright and related rights legislation that applies to your use. For other uses you must obtain permission from the rights-holder(s) directly, unless additional rights are indicated by a Creative Commons license in the record and/ or on the work itself. This Thesis has been accepted for inclusion in WVU Graduate Theses, Dissertations, and Problem Reports collection by an authorized administrator of The Research Repository @ WVU. For more information, please contact researchrepository@mail.wvu.edu. 


\title{
THE USE OF TECHNOLOGY TO DISPLAY STUDENT ARTWORK ONLINE
}

\author{
Elissa Dray \\ Thesis Submitted to \\ the College of Creative Arts \\ at West Virginia University \\ in partial fulfillment of the requirements \\ for the degree of \\ Master of Arts \\ in \\ Art Education
}

Victoria Fergus Ph.D., Chair

Ronald Aman, Ph. D.

Robert Bridges MFA, Curator

Morgantown, West Virginia

2014

Key words: Online gallery, children's art, display, art education

Copyright 2014 Elissa Dray 


\section{Abstract \\ The use of technology to display student artwork online \\ Elissa Dray}

This thesis was constructed to investigate the topic of displaying student artwork and projects in the online realm of art galleries. A research study was conducted questioning participants about their previous encounters with online art galleries and displaying student work. These participants were educators from various fields of study that created art related projects with their students. Participants were then introduced to the online art gallery, Artsonia and photographing student art. Benefits from joining Artsonia included parental contact, promotion of school art programs, possible fundraising opportunities, free lesson plan ideas, and increased student participation. Participants were also given the opportunity to explore the website on their own in pursuit of knowledge they found useful to their field of study. At the conclusion of the workshop participants were questioned about their experiences and what they found useful in the activity. This information was analyzed to find common links concerning displaying projects both traditionally and online. Participants in the research workshop noted that the website, Artsonia, was easy to navigate and thought the features were a useful teacher aid. Results from the workshop and readings found that educators felt it important to display work for student self-esteem and psychological development but have had difficulties with traditional display methods. Educators and scholars additionally thought it important to display student art as a technique for advocating art into an educational setting. 
Table of Contents

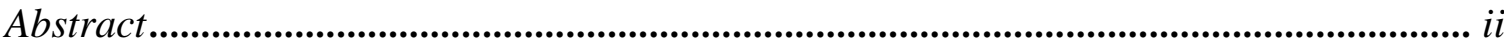

I. Chapter One

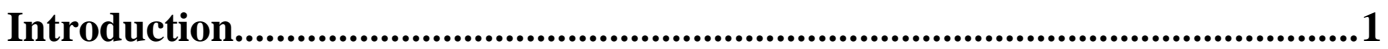

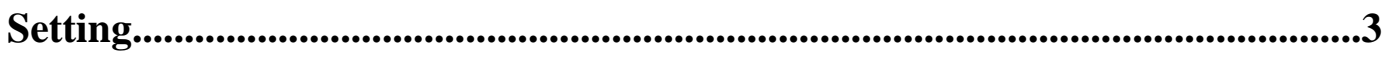

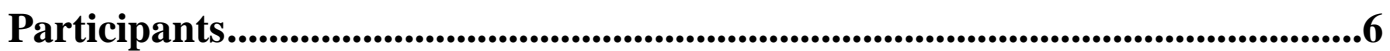

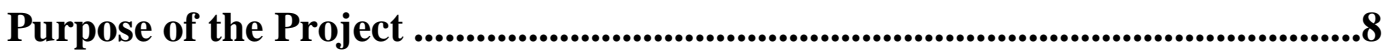

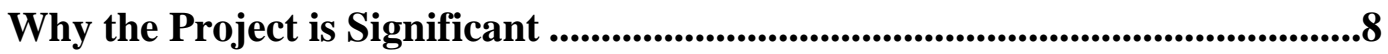

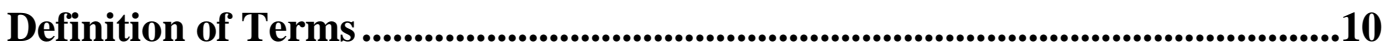

II. Chapter Two

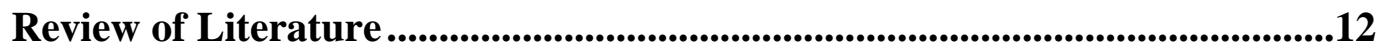

Benefits of Displaying Student Work ........................................................................12

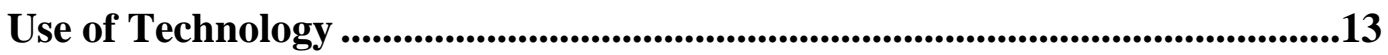

Summary of the Chapter ..................................................................................................14

III. Chapter Three

Methodology: Qualitative and Quantitative Data ................................................15

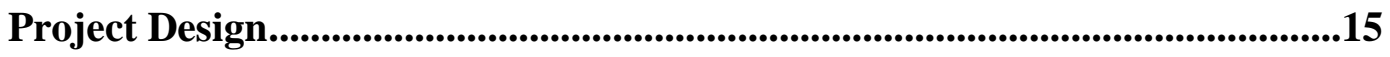

Data Collection and Material.......................................................................17

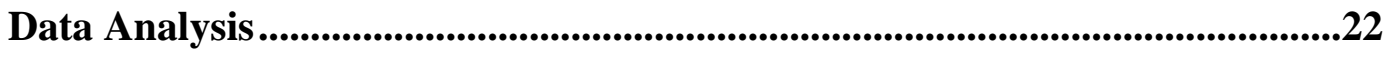

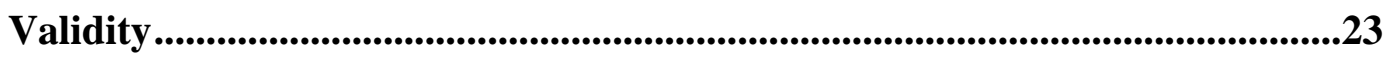

Summary of Outline of Upcoming Chapters...........................................................23

IV. Chapter Four

Artsonia LLC ............................................................................................24

Lesson Plans ..................................................................................................26

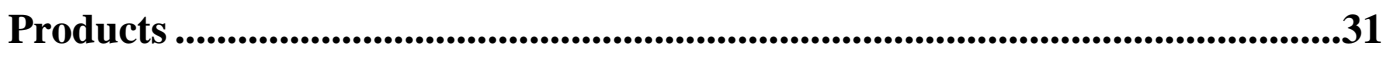

Collaborations and Promotions ......................................................................34

Additional Online Art Galleries ..................................................................36

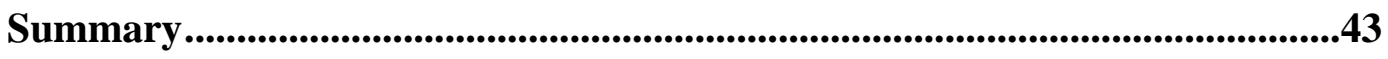




\section{Chapter Five}

Findings and Conclusions ....................................................................44

Descriptions of the Study ...............................................................................................44

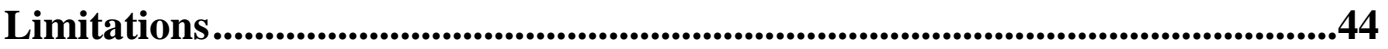

Summary of Findings .........................................................................................................44

Implications for Art Education.....................................................................................51

Implications for Education and Specialized Fields.................................................52

Recommendations for West Virginia Art Education ..........................................53

Recommendations for Further Study(ies) ................................................................54

Bibliography ............................................................................................................................55

Appendices ......................................................................................................................................58

Appendix A. Letter of Permission .......................................................................58

Appendix B. Research study advertisement .........................................................59

Appendix C. Instructions for creating an Artsonia account ..............................61

Appendix D. Instruction for creating a light box ..................................................81

Appendix E. Cover Letter ...............................................................................866

Appendix F. Participant consent form ......................................................................887

Appendix G. IRB Approval ......................................................................................91 


\section{Table of Figures}

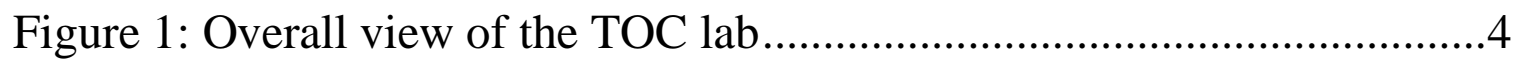

Figure 2: View from the main computer within the TOC lab ......................5

Figure 3: County map of West Virginia...................................................6

Figure 4: Screen shot of the lesson plan page of Artsonia.com ....................26

Figure 5: This is an example lesson plan found on the Artsonia website. ......28

Figure 6: Screen shot of the Artsonia gift shop webpage..............................32

Figure 7: Sample student print purchased from Artsonia ................................33

Figure 8: Promotional advertisement on personal Artsonia account. ...........36

Figure 9: Student art gallery page of Glencoe.com....................................37

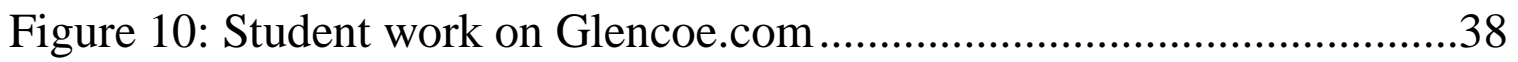

Figure 11: Student painting example with featured information. .................39

Figure 12: Example artist profile with biographical information. ................40

Figure 13: Home page of Mission: Renaissance website..............................41

Figure 14: Student artwork featured on the Mission: Renaissance website..41

Figure 15: Student artwork and gallery homepage of naturalchild.org.........42

Figure 16: Home page of www.artsonia.com............................................62

Figure 17: Screen shot of initial steps to create an Artsonia account ...........63

Figure 18: The selections of the country choices available..........................64

Figure 19: Screen shot for finding a teacher's participating school ..............65

Figure 20: Screen shot of page that requires a teacher's name and email .....66

Figure 21: Screen shot of Artsonia's privacy terms and conditions. ...........68

Figure 22: Security encryption displayed on Artsonia's webpage ................68

Figure 23: Screen shot of a successful teacher account creation. ...............69

Figure 24: Screen shot of Artsonia teacher account. ................................70

Figure 25: Yellow action box that appears toward the top of the screen ......71

Figure 26: Screen shot of biography portion of Artsonia .............................72

Figure 27: Options showing who can upload the student artwork ................73

Figure 28: Artsonia.com page with the options to upload student artwork ..74

Figure 29: Screen shot example of multiple uploaded student art pieces .....75

Figure 30: Student artwork uploaded, but not published to the website .......76

Figure 31: Artwork is uploaded but before an exhibit is created..................77

Figure 32: Option to return to your home page or upload more artwork......78 
Figure 33: Notification for sending parent emails or print take home slips..78 Figure 34: Screen shot of options for parent notification slips ....................79

Figure 35: Options for selecting students who would receive parent slips...79

Figure 36: Notification that parent slips are being processed ......................80

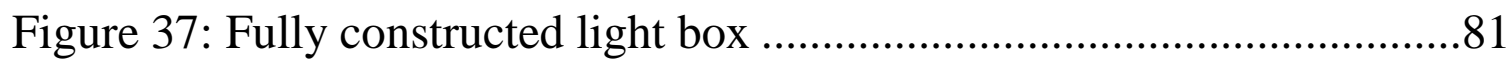

Figure 38: Pictures of materials used to create the light box .......................82

Figure 39: Method for lining up the edges of the light box ..........................82

Figure 40: Styrofoam cut for the back and top supports of the light box .....83

Figure 41: Picture of homemade light box without the top supports ............84

Figure 42: Picture of the homemade light box when completed....................84

Figure 43: Picture of the homemade light box with example of object ........85 


\section{Chapter One}

\section{Introduction}

Displaying finished works of art has been a tradition in the art world and society for hundreds of years. Artists apply to galleries, salons, exhibitions, and museums hoping to get their work out into the world for spectators to view. Student artwork is no different, but the responsibility mainly falls upon the teacher to display student work, until recently. Opportunities to display student work can include displaying within a school, art shows, festivals, and other venues.

From my experiences as a student and a teacher, space for display within a school was usually limited to bulletin boards, display cases, or school art shows that are up for a short amount of time. Available in school spaces were usually shared between all faculty members within that particular school. This meant that a student's work could be up for as little as one week to a few days depending on how many faculty members wished to use the display area at any given time. However, new display spaces for art have begun to emerge with the development of technology. Educators can photograph and upload their student works in online art galleries that could be viewed from anywhere that an internet connection was available.

There were additional problems faced by teachers who wanted to use traditional display methods. The school administration or janitorial staff may have discouraged the use of tape to hang work since it could leave a residue 
on the surface or be hard to remove. As an artist, there was also the concern of vandalism of artwork when it was placed in a public domain for viewing. Not every student was respectful of the property or creations of other students, which could result in damaged artwork. This defaced artwork could have been in the making for months or intended to be used in a portfolio for a college program application. Other times display areas were in an isolated location within a school that many students did not travel to unless they participated in certain classes, which resulted in the same viewers seeing the work every day.

The students spend a lot of time, thoughtfulness, and effort creating art so many, including myself, felt that it should be appreciated by the public, even for a short amount of time. I wanted to contribute to this activity by making it simpler for educators to use technology, especially if they were intimidated by it or unfamiliar with it, break down the website's procedures into simple directions or steps, and investigate possible reasons why teachers, of both general education and art education, were not using online galleries.

Computer based technology provided a new way to display student art with the development of online art galleries. However, many teachers were still not taking advantage of these new tools. After reviewing several online art galleries I decided to use Artsonia for the study. The purpose of this study was to question why teachers were not using online galleries to display student artwork and to help participants photograph and use technological equipment during a research workshop introducing the website 
www.Artsonia.com. This study asked 1) why teachers did not use the website, 2) if the participants displayed student work in general, 3) if the participants found the website easy to use at the conclusion of the study. Potential benefits for the participants and the educational field were that teachers will hopefully display their student work more often and to promote art education crosscurriculum.

Limitations to the study included a small number of participants, preference by participants to display work in a gallery setting, and a lack of art related assignments given to students. Educators and artists could still have a preference for displaying art in a gallery or exhibition. When art is photographed it loses such qualities as texture and detail. Colors can be modified in a photograph, appearing to be a different hue from the original

piece. Sculptures photographed cannot be fully viewed, especially sculptures in the round which are meant to be viewed from numerous angles. These aspects are lost when art is photographed and placed in an online gallery. More limitations are listed later on for both a small and large scale study. Participants learned that there were new ways in which they could share student work with others besides the traditional methods that they engaged in. I wanted teachers to be able to expand the viewing audience for student work.

\section{Setting}

The research study workshop took place at the John D. Rockefeller IV Career Center (JDRCC) located in Hancock County, West Virginia. Within 
the JDRCC, the workshop was located in the Technology Opportunity Center (TOC) lab. The JDRCC is a vocational school for high school students in Hancock County, West Virginia. The career center had the necessary equipment for every teacher that participated in the workshop. There were many high speed desktop computers with flat screen monitors for easier viewing. The head computer located in the front of the TOC lab was connected to a SMART@ board near the back of the room. Whatever was on the main instructor's computer also appeared on the SMART@ Board.

Students were able to watch what the instructor was discussing via the smart board without having to turn around to view the instructor.

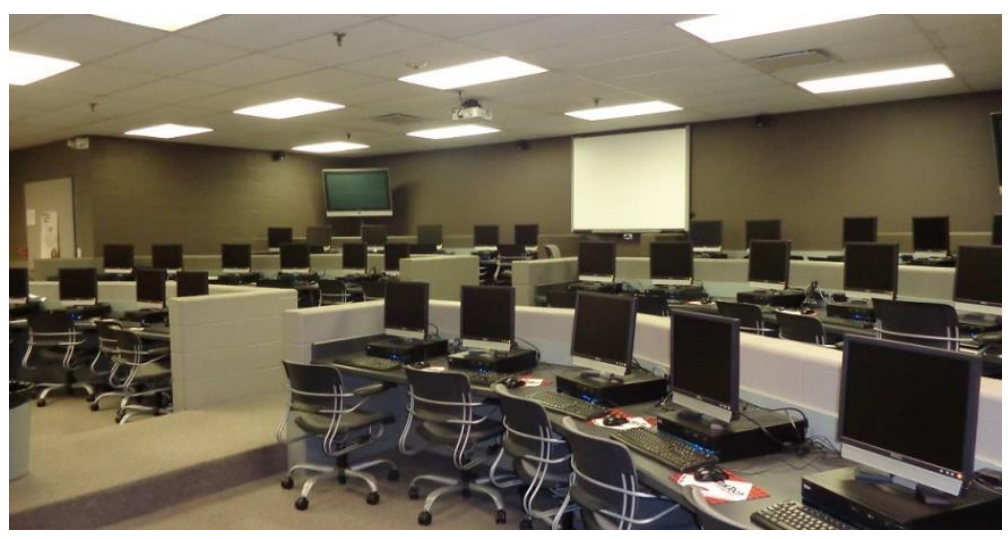

Figure 1: Overall view of the TOC lab 


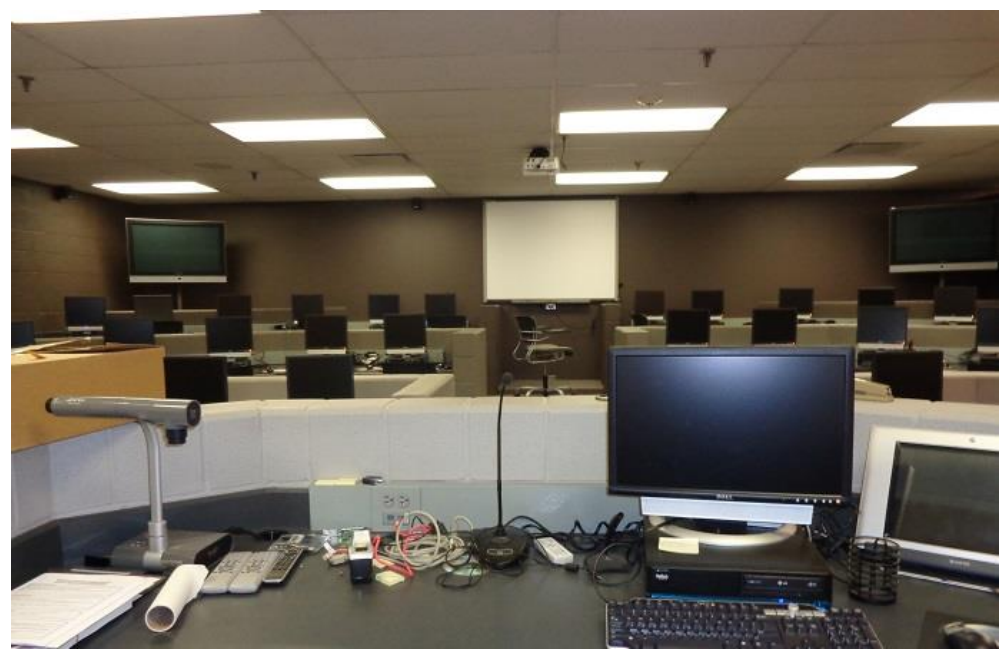

Figure 2: The view from the main instructor's computer within the TOC lab

During the study, high school students from both Oak Glen High School and Weirton High School travel to the career center daily to receive instruction in areas including health care, culinary arts, and auto body classes. Oak Glen High School is located in the northern part of Hancock County while Weirton is located in the southern part of Hancock County. The Weirton area borders Brooke County, West Virginia. The John D. Rockefeller IV Career Center was the median point between Oak Glen and Weirton. This fact, along with the fact that their computer facility had the proper equipment that was newer and high speed were my main reasons for choosing this location.

In order to use the John D. Rockefeller IV Career Center as the site for the study, I approached both the Assistant SuperIntendent of Hancock County Schools and the Principal of the John D. Rockefeller IV Career Center. I explained my thesis research and asked for permission to use the JDRCC as 
the location of the project. I informed them that this was a research project in which I would be collecting data and the reasons I chose the facility. Both individuals approved the decision to use the JDRCC as the location for the research workshop. A letter was composed stating that I could use the facility for research purposes (Appendix A). The workshop was only 1 day, for 2 hours and 15 minutes.

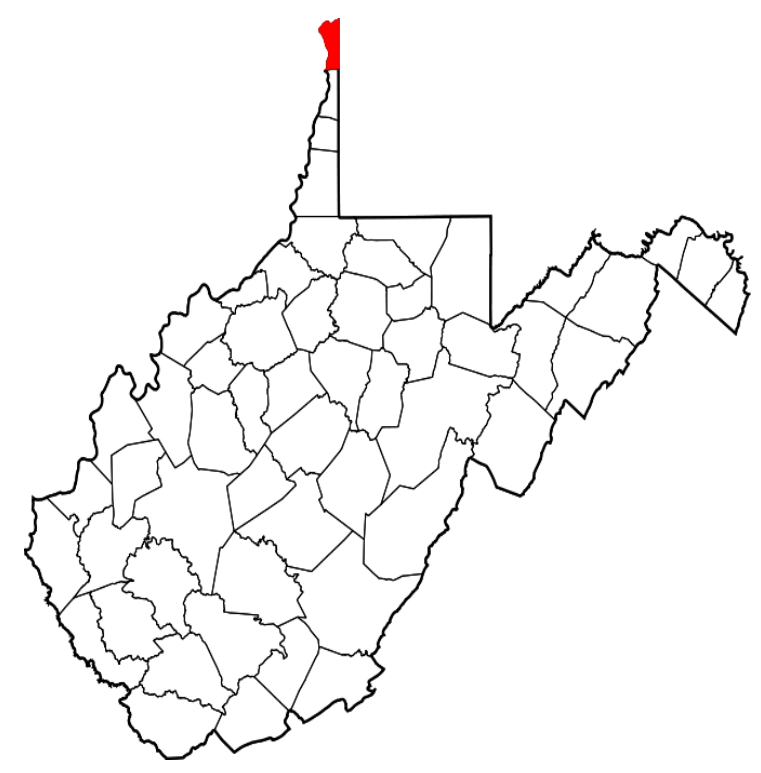

Figure 3: County map of West Virginia. The red area indicates where Hancock Count is located within West Virginia.

\section{Participants}

This research workshop was open to various subject specialists from Math, Science, English, Foreign Language, etc., .from pre-kindergarten through twelfth grade, from any school within Hancock County, West Virginia. From my experiences as a student and teacher I have found that not 
all of the most artistic, creative projects were assigned from art teachers.

Teachers from all areas of study created imaginative assignments that gave students the chance to display their ability to think critically, be inventive, and demonstrate their artistic skills. The maximum number of participants for the workshop was 17 in order to ensure that every participant could get the individualized attention that they required.

To inform participants of the research study, a short internet advertisement was created with the appropriate information (Appendix B). This advertisement was then emailed to staff members at all of the schools within Hancock County. These schools included: Allen T. Allison Elementary School, New Manchester Elementary School, Weirton Heights Elementary, Liberty Elementary School, Broadview Elementary School, Oak Glen Middle School, Weir Middle School, Oak Glen High School, Weirton High School, and the John D. Rockefeller IV Career Center.

The advertisement informed participants of the purpose of the workshop, the day/time of the workshop, how to register for the workshop, what fees or compensation were given for participating, what supplies the participants needed to bring with them, and contact information if there were any additional questions or concerns. Participants were asked to sign up on the Hancock County professional staff development website. 


\section{Purpose of this Project}

This project had several purposes. First, I wanted to introduce teachers from various educational fields to the world of online art display. With this introduction and workshop, I wanted to provide a how- to guide about the chosen online art gallery, Artsonia LLC (Artsonia) (Appendix C). During the research workshop I wanted to share information about photographing student artwork, both two- dimensional artwork and threedimensional artwork. Included with the photography information, I planned on displaying a homemade light box and handing out instructions on how to create the light box with simple materials (Appendix D). The light box was added to aid teachers who did not have access to a professional light box. After the workshop concluded I studied the data collected from the participants and tried to analyze why teachers were not using online art galleries. Along with the research project, I analyzed the features that Artsonia.com had to offer its members, specifically teachers along with students and their parents.

\section{Why the Project is Significant}

There are methods to decorating an Art classroom or elementary homeroom classroom with student work. Why use online galleries and websites to display student artwork? 
According to Burton (2010) many art teachers have discovered that the Internet offers a gallery largely unfettered in size, space, and access for their students' art. The online galleries provide unlimited space for any size project (both two-dimensional art projects and three-dimensional art), security from art vandalism, and global versus limited viewers. An instructor does not have to worry about matting or framing two - dimensional pieces of artwork, finding pedestals for three-dimensional pieces of artwork, taking the time to space out the artwork to guarantee everything fits, nor creating labels with the appropriate information for every piece entered in the exhibit. Traditional deinstallation of a gallery includes removing nails, patching holes, putting away pedestals, and preparing artwork for pick up. Exhibition de-installation was simplified with online galleries by deleting the exhibition off of the website or removing certain images.

There were several positive attributes of web-based galleries. Web-based student art galleries could be as modest as arrays of thumb-nail versions of student artwork that could be blown up to full- screen with the click of a mouse (Coates, 2009). This meant that a website could display several small images of student artwork, but if a viewer was specifically interested in one image they could choose one to blow up and observe in more detail. These larger images provided more detail and a viewer could change the piece they would have liked to view in mere seconds with the click of a mouse. Online galleries provided numerous viewing possibilities in a short amount of time. This resulted in the elimination of going to an actual space and art could be 
viewed from the comfort of one's own home or classroom Web-based galleries greatly expand the number of works of student and student artists who can be seen by viewers (Johnson, 2009). Coates (2009) also pointed out that the websites were updated frequently to attract repeat visitors. A neglected web-based gallery quickly loses appeal (Burton 2010). Avoiding neglect meant adding more art and attracting new viewers. Some web-based galleries could easily be linked to other art-related features or sites, such as a mission statement, lesson plans, or assignments (Joseph, 2009: Keiling, 2009: Prescott, 2009: Shannon, 2009: Wilke 2009). Web-based galleries were also linked to features such as museum web pages, artist biographies, or art related games.

\section{Definition of Terms}

\section{As defined by Merriam-Webster Dictionary, Eleventh Edition}

Artsonia- (as defined from www.Artsonia.com) children's gallery website that allows artwork by students to be put on display for a global audience.

Artwork- a painting, sculpture, print, photograph, etc. that is created to be beautiful or to express an important idea or feeling: an artistic work.

b: drawings, photographs, etc., that are included in books, magazines, and other printed materials. 
Blog- : a Web site that contains an online personal journal with reflections, comments, and often hyperlinks provided by the writer; also: the contents of such a site.

Gallery- 4 a: a room or building devoted to the exhibition of works of art. b: an institution or business exhibiting or dealing in works of art.

Light box- generally used to photograph small objects with a simple seamless white background; lighting an object well brings out details and provides pleasing highlights.

Media- 1: a medium of cultivation, conveyance, or expression.

Two dimensional- 1: having two dimensions 2: lacking depth of characterization.

Three dimensional- 1: of or relating to three dimensions 2: giving the illusion of depth or varying distances- used of an image or a pictorial representation especially when this illusion is enhanced by stereoscopic means 3: describing or being described in well- rounded completeness 4: true to life.

Website or Webpage- a group of World Wide Web pages usually containing hyperlinks to each other and made available online by an individual, company, educational institution, government, or organization. 


\section{Chapter Two}

\section{Review of Literature}

\section{Benefits of Displaying Student Work}

Why display student artwork at all? Displaying student artwork is both beneficial emotionally and psychologically to the students who create it.

An attractive art gallery effectively brings a school's art program and its students' achievements to the attention of other teachers, school administrators, and parents (Burton 2010). Burton is a member of the NAEA Distinguished Fellows, 2004. Many of the articles I have read addressed the need to display and appreciate student work for supportive reasons, both emotional and psychological. According to LeeKeenan \& Nimmo, 1993, learning through the arts enabled children to make connections and relations between child, parent, teacher, and community. The effort children put into the projects and the overall quality of their work is affected by how adults treat their art projects (Katz 1993). When children realize that their work is respected, they become aware of their self-worth, and as a result, children's self-esteem increases (Kim H., Park E., and Lee J. (2001)). Another reason for art exhibitions was the promotion of keeping art in schools. Richard and Lemerise (2001) noted that after 1960 art exhibitions often appeared to defend and advocate public schools as a place where students could develop visual thinking as we as creative imagination. 
These were common themes within most of the readings about displaying student work and advocating for art within education. I wanted to look at the technical components of displaying work more than the emotional. Not only was displaying art beneficial, but viewing art had positive attributes. Kerry Freedman, Professor and Head of Art and Design Education at Northern Illinois University, and other scholarly contributors have argued that making and critiquing art helped students to think, interpret, understand, and create meaning critically to support conceptual learning (Lu, 2013; Efland, 2002; Freedman, 2003; Marshall \& Vashe, 2008). These galleries gave viewers yet another window into the world of art and creation.

\section{Use of Technology to Show Student Work}

Technology is an important part of today's society, including within the art world. Not only was technology used to create (graphic design) and teach about art (Power Point ${ }^{\circledR}$ and museum websites), but was being used for display purposes. The research journal of the National Art Education Association, Studies in Art Education, recently published a study about using 3D virtual game systems (such as Second Life or Sims) as an art medium or exhibition space (Lu 2013). Second Life is a multi-user virtual world or simulated environment where everything is built by avatar-residents, except the basic land (Robbins \& Bell, 2008). The study was conducted by having students use avatars (virtual models that represent a person) to create virtual artwork then exhibit the work in a virtual gallery. The participants were then interviewed about their experience. Lu (2013) explains that 3D virtual 
worlds can help global artists individually or collaboratively create a piece of virtual art or an entire space and allow global audiences to attend the exhibit and participate in art events. Participants were able to create digital art then display it for other avatars to view in the virtual gallery, which many of the participants claimed was the most exciting and enjoyable part of the study ( $\mathrm{Lu}$ 2013). An additional edition of Art Education explored such technological tools as stop-motion animation, blogging, Alternate Reality Gaming, YouTube LLC., and Second Life. In a recent article titled, "The Real Deal: How Three Teachers Use Artsonia in their Classrooms" of The Art of Education, an online art magazine, one art educator explained that her student had family in India. That student's family was elated because they were able to view her artwork since the educator posted it to the website, Artsonia.

\section{Summary of the Chapter}

From the literature reviewed it can be concluded that displaying art was beneficial to a child's emotional and psychological development. Receiving respect and praise for their artwork boosted the student's self-esteem. A boost in self-esteem encouraged students to further their artistic knowledge.

Technology has aided the art world and teachers by providing an additional realm to display work. These new spaces included simulated life games, video games, and websites. New technology art spaces were available to artists, students, and viewers of all ages. Educators could exhibit the work of every student they instructed instead of just a select few whose work would fit 
inside of a display case. This new method of display allowed for a longer time period in which to view artwork and could be available to a wider, global audience versus a traditional gallery method available to only those who visited the gallery in the selected time period.

\section{Chapter Three}

\section{Methodology: Qualitative and Quantitative}

Data collected for the study was both qualitative and quantitative. The qualitative data concerned feelings and experiences while the quantitative data provided numbers and statistics. I felt it important to know the number of participants that practiced displaying art but I also wanted to gain the knowledge of their experiences. The questionnaires provided a way to have both qualitative and quantitative data. Participants were able to contribute information or ideas that I did not think to include.

\section{Project Design}

The workshop was designed to appeal to any educator who actively participated in art related activities with their students. These activities did not have to be purely the creation of artistic pieces but could involve the use 
of art media, technique, or investigation into creative approaches. The assignments themselves could involve any school subject such as Math, Science, English, Health, etc. I wanted these participants to learn about another outlet that allowed them the possibility to display their student's works outside of the traditional in- school setting.

Participants were asked to first come to the John D. Rockefeller IV Career Center, specifically the TOC lab. Participants were allowed to choose what computers they worked at; there were no assigned seats for this study. When all participants had arrived, they were given the cover letter (Appendix E), instructions to follow along with, and the pre-workshop survey. Participants were asked to fill out a consent form prior to starting (Appendix F). After the surveys were completed and collected, I then demonstrated how to log onto Artsonia, create a teacher account, and upload student artwork. All of these procedures were done using the main computer that projected my actions and steps onto the SMARTC Board to allow easy follow along guidelines. After I demonstrated all of these steps, I went around to each participant to make sure they understood the instructions and if they had any questions. Participants were then given some time to explore the website without direction. During this time, I explained about the fundraising and lesson plans available to teachers as an educational aid.

After a few minutes I displayed the various ways in which teachers could photograph student projects, both projects that are two- dimensional and three- dimensional. I described how I had constructed the light box and what 
materials were needed. At the conclusion of the workshop, I gave time for additional questions and idea input. Participants were then given the exit survey. These surveys were collected and filed with the pre-workshop surveys for analysis.

\section{Data Collection and Materials}

Participants were asked to fill out two short surveys for the collection of data. One survey was given prior to instruction and one survey was given at the conclusion of the workshop. Surveys were only half a page to a page long in length. Surveys were anonymous with no name or education field (ex: art, math, science) required. Each survey had an additional comments section in case there was advice or thoughts about the workshop that were not included in the questions on the surveys. The following were the questions that participants were asked to answer voluntarily.

\section{Pre-workshop survey:}

1. Have you ever viewed any websites that are online galleries?

Yes or No

If you have not viewed these websites, can you please explain why not?

2. Have you ever had to get creative in how you display student work because of a lack of display space or strict displaying rules?

Yes or No 
If you have had to get creative with your display can you please give a description of the process you had to go through to display the work?

2. Have there ever been any obstacles with displaying work? Yes or No

If there have been obstacles can you please name what they have been?

3. Has there ever been a particular piece of art that was hard to display (maybe because of size, weight, or fragility)?

Yes or no

If there has been a difficult project to display can you please describe the project?

4. Do you feel you have adequate traditional display space?

Yes or No

Why or Why not?

5. Do you share display space with other staff members? Yes or No

Can you please give an approximate number of staff members that you have to share display space with?

6. Do you feel that it is important to display student work? Yes or No

Why do you feel that it is important to display student work?

7. Do students have access to technology? 
Yes or No

What kind of technology do your students have access to?

8. Has anyone ever brought up the idea of using an online gallery to display student artwork?

Yes or No

9. Which level do you teach? (please circle one)

Elementary, middle school, high school

11. If you do not use online galleries, can you please tell why?

a. I have never heard of online art galleries.

b. I do not have the necessary technological tools.

c. I do not have time.

d. other:

12. Additional comments:

\section{Exit Survey}

1. Do you feel your school has the necessary tools available to display art online if you wanted to continue to display online? (Tools could include high speed computers, cameras for photographing artwork, scanners, or even quality internet connections)

Yes or No 
What technological tools do you have access to?

2. Does your class have access to lap top stations?

Yes or No

3. Does your class have access to a computer lab?

Yes or No

Is it easy to schedule a time for your class to enter the computer lab?

4. Have you ever viewed an online gallery or website that promoted student artwork?

Yes or No

Did you feel the website was organized and easy to use?

Why or why not?

5. Did you feel that using the online gallery was more difficult or easier than a traditional gallery? Or display? Please circle one:

Easier, somewhat the same, Harder

6. Did you find this workshop helpful?

Yes or No

What about the workshop did you find helpful?

Is there anything you feel needs to be simplified or changed about the instructions in using the website?

7. Would you use this display method (online gallery) again? Yes or No

8. Which level do you teach? (please circle one) 
Elementary, middle school, high school

9. Additional comments:

Numerous materials were provided for participants in the research study. Participants had to provide few supplies for the study. I did not want participants to have the burden of transporting too many materials nor having to purchase items with their own funding.

\section{Materials used for the workshop included:}

- Desktop computers, specifically Daktech ${ }^{\circledR}$ brand.

- $\quad$ SMARTC Board with projector which is hooked up to the main desktop computer used by the instructor of the class. This made instruction simpler because the participants could merely watch the steps of the lesson projected onto the SMART@ Board.

- Example homemade light box (Appendix D) with light source.

- White paper for a photograph background of the 2-dimensional art example (I chose white, but any color could be used depending on what the person photographing the work would like or what color will make the artwork stand out from the background.) The paper size should be larger than the artwork that is being photographed.

- Thumb tacks to place the art against the background but not used to pierce the artwork.

- Pencils

- Pens 
- Erasers

- Scratch paper to take notes

\section{Each participant was asked to bring three items:}

- An example of the projects that they created with their students. The assignments could be three-dimensional or two-dimensional, in any art media form.

- A technological device of their choosing to take the photographs of their student artwork. The participants could use a digital camera, $i P a d \AA$, or cell phone. If a participant chose to use a digital camera they had to provide a universal serial bus (usb) cable to upload their photos since the Daktech ${ }^{\circledR}$ desk top computers do not possess a card reader.

\section{Data Analysis}

At the conclusion of the workshop, all surveys were collected from the participants. Survey answers were then analyzed and results were compiled. I asked that teachers expand upon their choices survey answers. Written comments and suggestions were noted and recorded. These comments provided insight into the experience of the participants and what could be done to improve the instructions for educators who wanted to learn about Artsonia. The comments also provided knowledge about the previous 
experiences that teachers have had with both displaying student work and if they have viewed online art galleries previous to the Artsonia workshop.

\section{Validity}

The workshop was completely voluntary; participants were not forced to sign up for the workshop. All questions that participants were asked were related to the topics of teaching and displaying student work. Since not every participant was in the field of art education, no questions were aimed at the process of making art, knowledge of art techniques, knowledge of art history, or the ability to critique art. Participants did not have to answer any questions they did not understand or that made them feel uncomfortable, or did not want to answer. Surveys were kept anonymous with no name required nor indication of the field that the participant teaches. I possessed no samples of the participant's handwriting, so even if a participant chose to comment, their handwriting could not be identified.

\section{Summary and Outline of Upcoming Chapters}

In this section I explained how the project was designed, listed the survey questions for both the pre-workshop survey and the exit survey, listed the materials used for the workshop, discussed how data was analyzed, and how 
validity was ensured. There were blind spots and limitations to the study, but I believed many of the problems could be fixed.

In chapter four I will discuss the website used for the research project, Artsonia.com, and a list of features on the website. I will also provide a list of other art gallery websites and reports of their attributes and limitations. I will discuss what I believe are the implications for West Virginia art education, education outside of the art field, and art education in general. Additionally, I have listed possible further studies that could be conducted. Included in the end of the paper within the Appendices will be instructions on creating an Artsonia teacher account, directions on uploading student artwork to Artsonia, and a guide on creating a small light box for photographic purposes.

\section{Chapter Four}

\section{Artsonia}

According to their website, www.artsonia.com, Artsonia was the world's largest kids art museum online. Artsonia was a website specifically designed to display the work of students (pre-k through high school). The website was established in the year 2000 and has continued to grow. Artsonia was cofounded by three engineers, two with electrical engineering degrees while the third had an aerospace engineering degree. As of December 2013, they had 23,703,088 artworks on display, 4,219,777 fan club members, 83,838 teachers 
using the website to display work, and 4,980 lesson plans available for teacher use. Artsonia listed the following points on their website as advantages to using their services:

- Kids develop a new sense of pride and feel like famous artists published in a museum!

- Family and friends view the artwork, join fan clubs and leave personal comments for the artists.

- Schools earn $20 \%$ when parents purchase custom keepsakes with their child's artwork - a great fundraiser for your arts program!

- Thousands of Art Project Lesson Plans have been submitted by teachers just like you, and are available as a resource for your classroom!

Artsonia had its own teacher blog link. This blog allowed teachers to share opinions, information, comments, ideas, and articles. Parents could start a fan club and view the art that their child created. There was also a gift shop in which anyone was able to order a variety of products with student artwork of their choosing printed on the product. When an item was purchased, $20 \%$ of the sales went to the school that the artwork was chosen from. 


\section{Features of Artsonia- Lesson Plans}

Artsonia.com provided thousands of lesson plan ideas for

educators. As displayed on the left of the Figure 4, newer lesson plans were

prominently displayed on this feature page. However, lessons could be browsed

by age of students (ranging from Pre-K to high school), a vast variety of media,

school subjects, or the names of educators who post an abundance of lesson plans

at one given time, deemed "Power Planners".

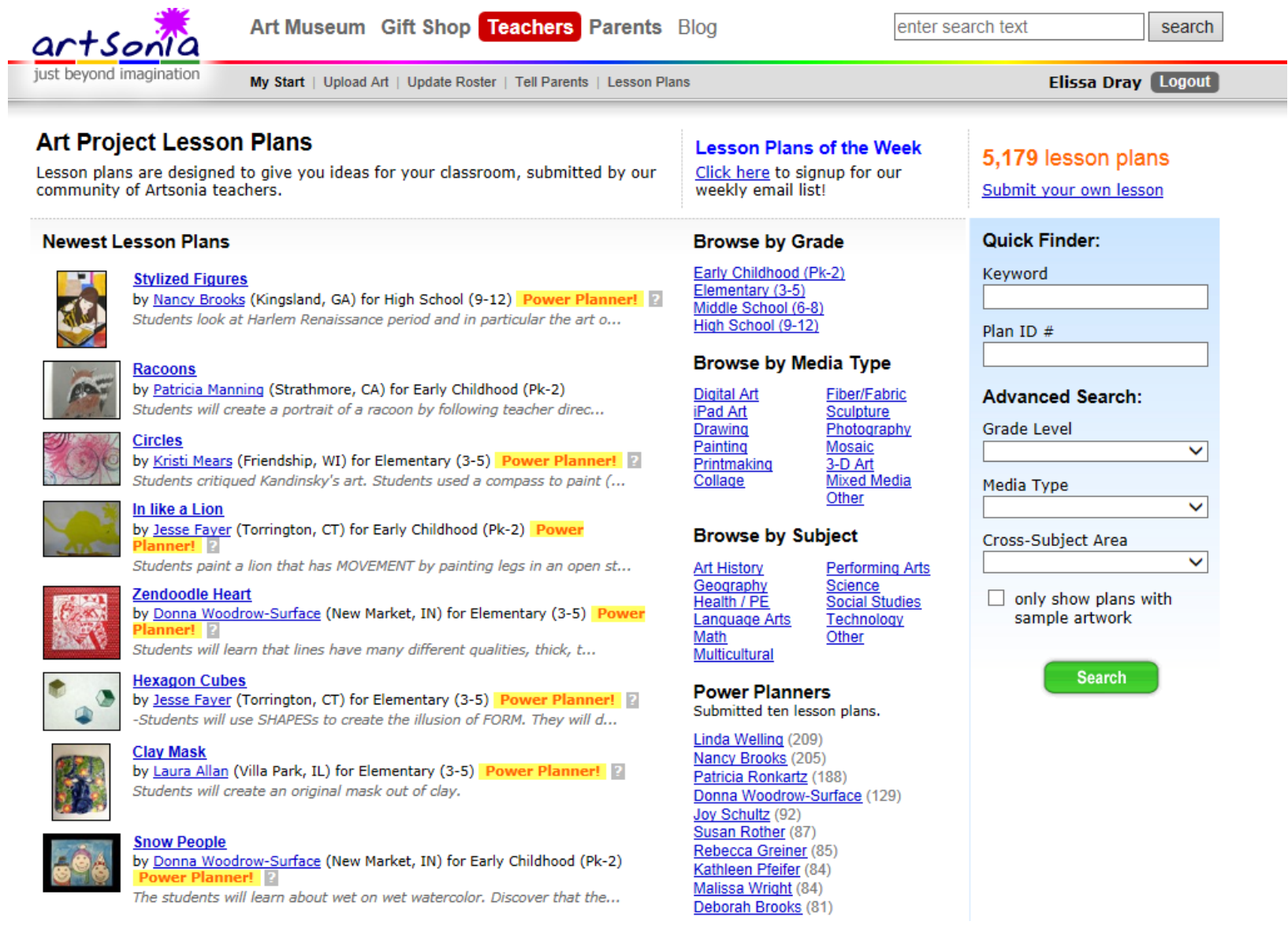

Figure 4: Screen shot of the lesson plan page of Artsonia.com 
Most lesson plans were typed out in a detailed layout that included: name of the instructor who posted the plan, what school the instructor taught at, the name of the lesson, age of the target audience students, pictures of example projects, other subject integration possibilities, content standards, objectives, assessment, rubric, materials, procedures, discussion questions, resources, and follow up activities. However, not every plan followed this format and some plans were shorter depending on how much the instructor wanted to include. The following (Figure 5) was an example lesson plan found on the Artsonia website. 


\section{Lesson Plan: Mummy Cats}

by Erica Lang Power Planner!

from Della Lamb Elementary School (Kansas City, MO)

submitted Dec 3, 2013

for grade level » Early Childhood (Pk-2)

duration $\gg 2$ sessions (about 30 minutes per session)

media type » Drawing

\section{sample student artwork}
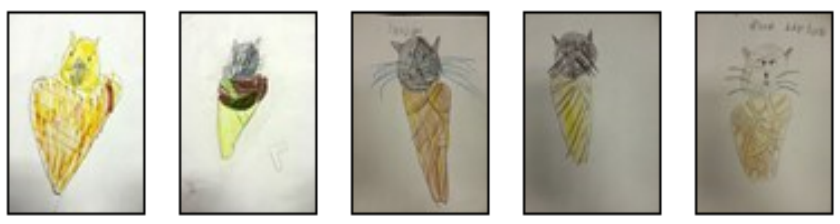

Click here to view all 82 artworks.

\section{curriculum integration}

subject integration: Geography

\section{content standards:}

1-A (PK - 4) Students know the differences between materials, techniques, and processes

2-C (PK - 4) Students use visual structures and functions of art to communicate ideas

3-A (PK - 4) Students explore and understand prospective content for works of art

3-B (PK - 4) Students select and use subject matter, symbols, and ideas to communicate meaning

4-A (PK - 4) Students know that the visual arts have both a history and specific relationships to various cultures

4-B (PK - 4) Students identify specific works of art as belonging to particular cultures, times, and places

4-C (PK - 4) Students demonstrate how history, culture, and the visual arts can influence each other in making and studying works of art

5-B (PK - 4) Students describe how people's experiences influence the development of specific artworks

5-C (PK - 4) Students understand there are different responses to specific artworks

6-A (PK - 4) Students understand and use similarities and differences between characteristics of the visual arts and other arts disciplines

6-B (PK - 4) Students identify connections between the visual arts and other disciplines in the curriculum

\section{objective / assessment}

objective: Unit Goal/Big Idea: Students will observe and discuss examples of abstract drawing, painting, and sculpture as it relates to life and/or death in different countries. Lesson Objectives: 1 . Students will read information about mummification using a story worksheet. (HC1A2) 2. Students will design a preliminary sketch of a mummified cat after looking at a teacher example. (PP1A2) Lesson Objectives: 1 . Students will compare lifelike and abstract animals while working in table partners. (AP1A2, AP1A2, and HC1B2) 2. Students will create a colored pencil drawing of a mummified cat after looking at a teacher example. (PP1A2 and HC1A2)

assessment: Work ethic - did the student try their best on both days? (1 point) Drawing - did the student draw the lines correctly? (1 point) Cat - is the cat shape recognizable as a cat? (1 point) Coloring - did the student use the correct colored pencils to color in the color choice the right way? (1 point)

rubric: none specified 
materials \& procedure

\section{materials:}

Pencils

Erasers

$9 \times 12$ white drawing paper

Neutral color colored pencils

\section{procedure:}

1. Students will be introduced to the lesson by viewing vocabulary words and visual examples of those words if applicable.

2. The teacher will write each vocabulary word on the board and will then say it one time. (listening)

3. The students will repeat the word. (b) (speaking)

4. The teacher will follow up by showing an example or explaining an example of each word.

5. After all of the vocabulary words have been discussed, the teacher will review the words one more time by saying them and having the students repeat them quickly.

6. After vocabulary has been covered, the teacher will hand out the story worksheet.

7. The teacher will select students randomly to read individual sentences and will ask questions throughout the reading. (c, d, e, and f) (reading)

8. Once the reading is finished, the teacher will show an example of the work the students will be creating.

9. The white drawing paper will be handed out with a reminder to the students to put their names on the paper.

10. First, the students will write the word "mummification" on the back of their paper while looking at the word written on the board. (writing)

11. The teacher will demonstrate how to draw a cat's head on the board.

a. Draw a circle.

b. Draw triangle shapes for the ears. Add lines to show the inside of the ear.

c. Draw the eyes using curved lines and small circles.

d. Color in the eyes.

e. Draw the nose using curved lines and an organic shape.

f. Color in the nose.

g. Draw the mouth using curved lines.

h. Draw the bottom part of the mouth and erase the overlapped line.

i. Draw whiskers using straight lines.

12. The students will draw a cat's head on their own papers.

13. Next, the teacher will demonstrate how to draw the mummified body of the cat on the board.

a. Draw the shoulders using curved lines. (a) (speaking)

b. Draw the body using straight, diagonal lines to make a triangle shape. (a) (speaking)

c. Draw the end of the body using a straight, horizontal line at the end of the triangle shape. (a) (speaking)

14. The students will draw the body of the cat on their own papers.

15. Then, the teacher will demonstrate how to use straight, diagonal lines to create the wrapped cloth on the mummy cat's body. (a) (speaking)

16. The students will draw the cloth on the body on their own papers.

17. The teacher will monitor the students during each step by walking around and giving compliments and help when necessary.

18. The students will work until the end of class time.

19. When class time is over, the students will put away their supplies.

20. The teacher will chose one student to collect the work for the teacher to put in the work folder for that class.

21. Once the work and supplies have been put away, the teacher will call the students to line up by color tables. 
1. First, the students will be introduced to the lesson by reviewing 2 vocabulary words (Egypt and mummification)

2. The teacher will show the examples of the vocabulary words if applicable and will give students and opportunity to say the vocabulary words. (speaking)

3. After several guess have been made, the teacher will tell the students the right word and will have them repeat it. (speaking)

4. Then, the teacher will introduce 3 new vocabulary words. (realistic, abstract, and portrait)

5. The teacher will write the new vocabulary words on the board.

6. The teacher will say the word and the students will repeat it back. (listening and speaking)

7. Examples of the vocabulary words will be shown if applicable.

8. After all of the vocabulary words have been covered, the teacher will review the new words by saying them once more and having the students repeat them. (listening and speaking)

9. Once vocabulary has been covered, the teacher will display Hare by Albrecht Durer and

Cat and Bird by Paul Klee side by side through the projector.

10. The teacher will hand out small white boards to each table, along with dry erase markers.

11. The students will work in groups at their tables to discuss the similarities and differences of the two pieces. (c, $d$, and e)

a. The teacher will choose one student to read one of the text-based questions as the other students are looking at the artworks. (reading)

b. The students will have 10 - 20 seconds to talk about the answer while working together as part of a group.

(listening and speaking)

c. Then, the teacher will choose one student to write the answer on a small white board. (writing)

d. When time is up, the students will reveal what they wrote on their whiteboards.

e. The teacher will share these answers with the rest of the class.

f. Next, the teacher will ask another question and this process will repeat for all questions.

12. After the discussion, the teacher will select 2 students to help hand out the drawing the students started the previous class period.

13. Next, the teacher will display the teacher-made example.

14. After everyone has their paper back, the teacher will demonstrate how to color in the mummified cat drawing, paying attention to color choice.

15. The students will start working on coloring their drawings.

16. The teacher will walk around the class to help with any questions and give feedback as the students are working.

17. They will work until the end of class time.

18. At the end of class, the teacher will select one student to help collect the artworks and another student to collect the colored pencils.

19. Once the work and supplies have been put away, the teacher will call the students to line up by color tables.

\section{additional help}

\section{discussion questions:}

a. What type of line is this? (answers will vary based on what line is asked about)

b. What are some types of organs? (heart, lungs, stomach, etc...)

c. What do you need to take out of the body? (organs) (type 1 questioning)

d. What do you cover the body with? (cloth) (type 1 questioning)

e. Why do you think they cover the body in cloth? (student opinion) (type 3 questioning)

f. How many days does it take to mummify something? (70) (type 1 questioning)

a. What is the name of a picture of a person? (portrait) (type 1 questioning)

b. Do you think this could be one of Klee's artworks? (yes - student opinion) (type 2 questioning)

c. Identify the subject of these two artworks. (animals, cat, bunny, rabbit, ect...) (type 3 questioning)

d. Compare the animals in each piece. (animals, furry, eyes, ears, student opinion) (type 2 questioning)

e. Contrast the animals in each piece. (bunny/rabbit, cat, real, made-up, student opinion) (type 2 questioning)

Figure 5: This is an example lesson plan found on the Artsonia website.

followup activities: none specified 
This particular teacher included explicit procedure instructions and there were 82 examples of this project that could be viewed. Some lesson plans had no example pictures provided and instructions were less clear.

There were other tools available to teachers that could aid in communicating with parents and students. An optional newsletter could be created on the website to inform parents about specific classes, shows, and events. Parents were able to view positive comments left by the teacher with the Teacher Feedback tool. Finally, the teacher was able to select certain student works to create a progress report. In these reports a teacher was able to comment on strengths, constructive criticism, or overall improvements the students were making with their work. This report could be printed out or emailed to parents.

\section{Products}

There were a variety of products offered on the Artsonia website that family members, friends, or fans could purchase. 


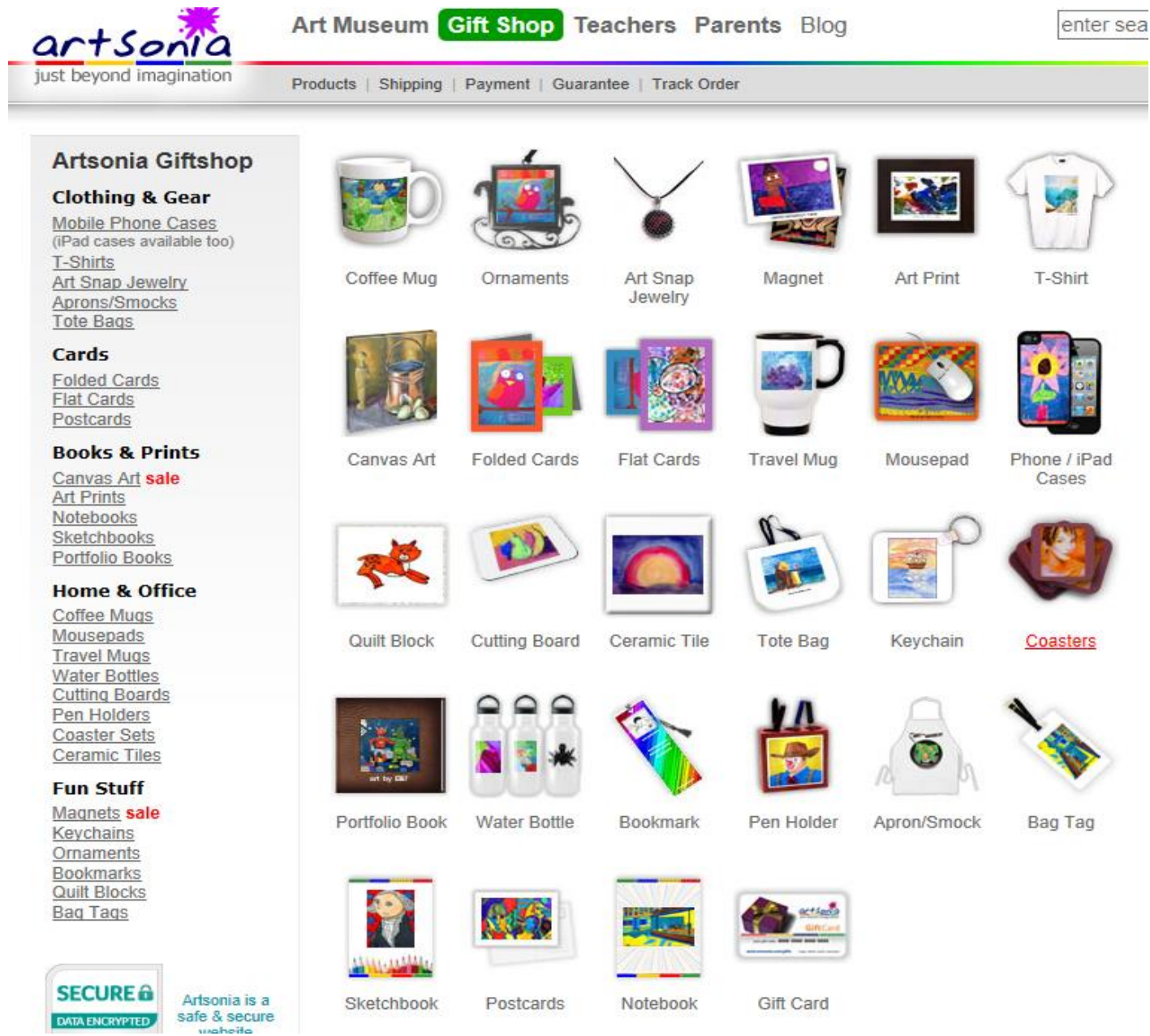

Figure 6: Screen shot of the Artsonia gift shop webpage.

Figure 6 featured samples of the products that were available to purchase directly from the Artsonia website. As stated on Artsonia's gift shop guarantee page, "Artsonia provides gift merchandise for parents with their own children's artwork as a continuation of its mission to boost kids' pride in their work and to increase parental involvement in their children's education and achievements." 
Figure 7 is a print purchased from Artsonia by an instructor at Oak Glen High School. The small caption underneath the artwork reads, "Artwork by Avery". This print was received in a white cardboard envelope. Proceeds from purchases went towards the school that the artwork was submitted from. This method provided a possible way to improve art education funding to a school.

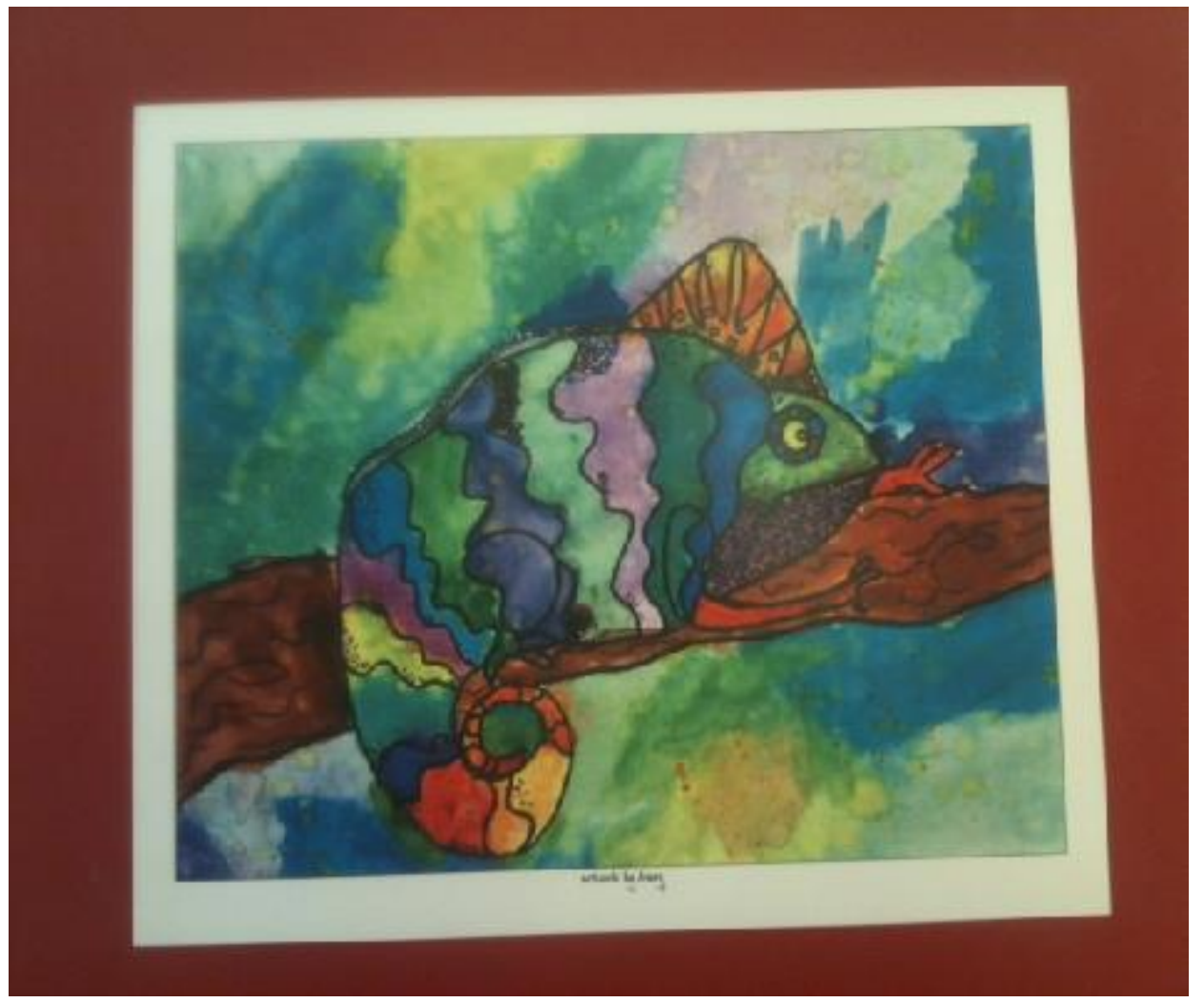

Figure 7: Sample student print purchased from Artsonia. 


\section{Collaborations and Promotions}

Most recently Artsonia sponsored an art exhibition for members of the National Art Education Association (NAEA). The artwork was included in the Spark Gallery at the 2014 NAEA National Convention taking place in San Diego, California. The theme of the 2014 convention was "Spark! Fusing Innovative Teaching \& Emerging Technologies". According to an NAEA email, "the gallery, initiated by the NAEA Art Education Technology (AET) Issues Group and sponsored by Artsonia, will be available for viewing through the NAEA Convention Mobile App, online, and on the "big screens" prior to "Convention General Sessions." The executives of Artsonia also provided an $11 \times 14$ print of your artwork as a gift for teachers who participated in the gallery. They were available for pick up at the convention.

Artsonia encouraged teachers to become members of the National Art Education Association by entering their account numbers into their Artsonia account or by signing up for an NAEA membership through a link on the Artsonia website.

Artsonia sponsored a student artist of the week weekly. According to the Artsonia webpage, this was the process for the artist of the week selection and contest.

\section{Tuesday:}

Artsonia selects twelve random art submissions in each of four different age groups from artwork submitted the previous week. 


\section{Wednesday-Saturday:}

Voting is open to the general public and limited to one vote per computer, per day.

\section{Sunday:}

Winners are announced and featured on the Artsonia homepage!

\section{Super Prizes!}

Each week, Blick® Art Materials generously donates a \$100 gift certificate to each winning school and a $\$ 50$ gift certificate to each winning artist. (That's more than $\$ 20,000$ in prizes for the school year!)

This is not the only promotion that Artsonia provided for educators and users. Through March $31^{\text {st }} 2014$, any new participant could post their $50^{\text {th }}$ piece of artwork on Artsonia and be entered into a drawing to win a free iPad®. It is called their "Try Us Out" promotion for the month of March. In addition to being entered to win the iPad®, Blick® Art Materials provided a $\$ 35$ gift card to every teacher who successfully published his/her 50th piece of student artwork onto the website. 


\section{Contest \& Exhibition Opportunities}

Further showcase your students' artwork! ?

\section{March Try-Us-Out Promo NEW}

Earn a $\$ 35$ Blick Art Materials gift-card and a

chance to win an iPad by publishing 50 artwork by March 31 ! View details

You published 30 artworks to date.

Keep going: you just need 20 more to qualify for this promo!

Figure 8: Promotional advertisement on personal Artsonia account.

Artsonia was also open to collaborating with companies on different promotions.

They encouraged contact with their executives to discuss possible ideas for working with schools and students. Artsonia was actively trying to become part of the art education world through these collaborations with art supportive groups and companies. They have provided opportunities for both teachers and students to promote student artwork, as well as opportunities for parents or guardians to be supportive.

\section{Additional Online Art Galleries}

There were additional websites that provided opportunities to display student artwork. The websites include McGraw-Hill@ Online Art Gallery, Mission Renaissance ${ }^{\circledR}$, and The Natural Child Project@. I believed these websites were not as developed as Artsonia, meaning they did not offer as many features or have as much student work published on them but still offered educational chances for students. 


\section{a. Glencoe $\odot$ Online Art Gallery}

The McGraw-Hill Company@ offered a student art online gallery. This gallery spoke more to students. The McGraw- Hill Company@ provided educational utensils such as textbooks and digital learning aids for students and educators. The homepage of the gallery website directly addressed students and advised that they, the student, ask a teacher to sponsor them in order to submit their artwork to the gallery. Artwork types featured on this website included: drawing, painting, mixed media, and digital art.

Digital art included work created using art software (Photoshop) and photography. To gain access to a gallery, you simply clicked on the art media you wish to have viewed.

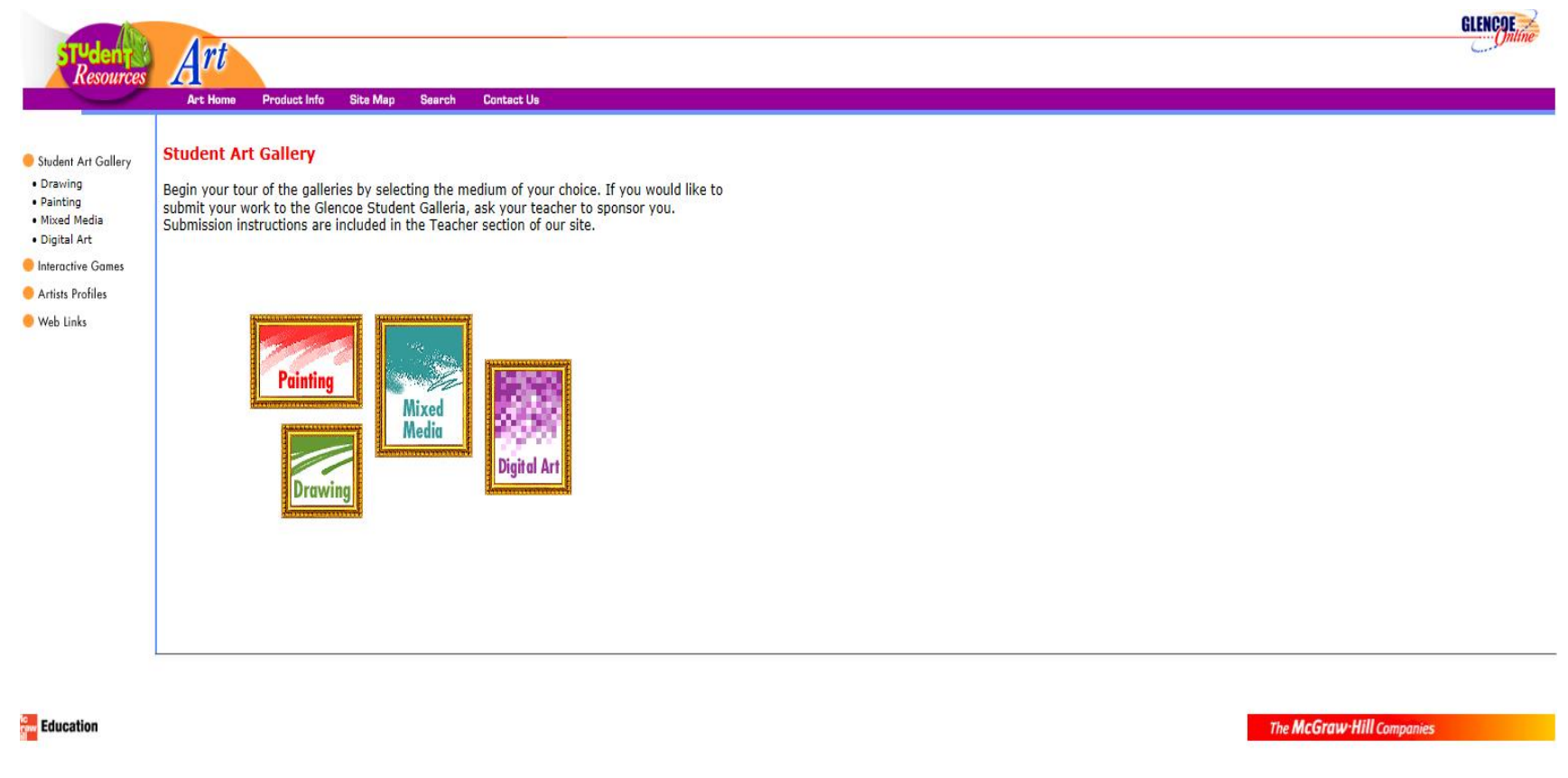

Figure 9: Student art gallery page of McGraw Hill@ Online Art Gallery, also under the company name Glencoe(C). 


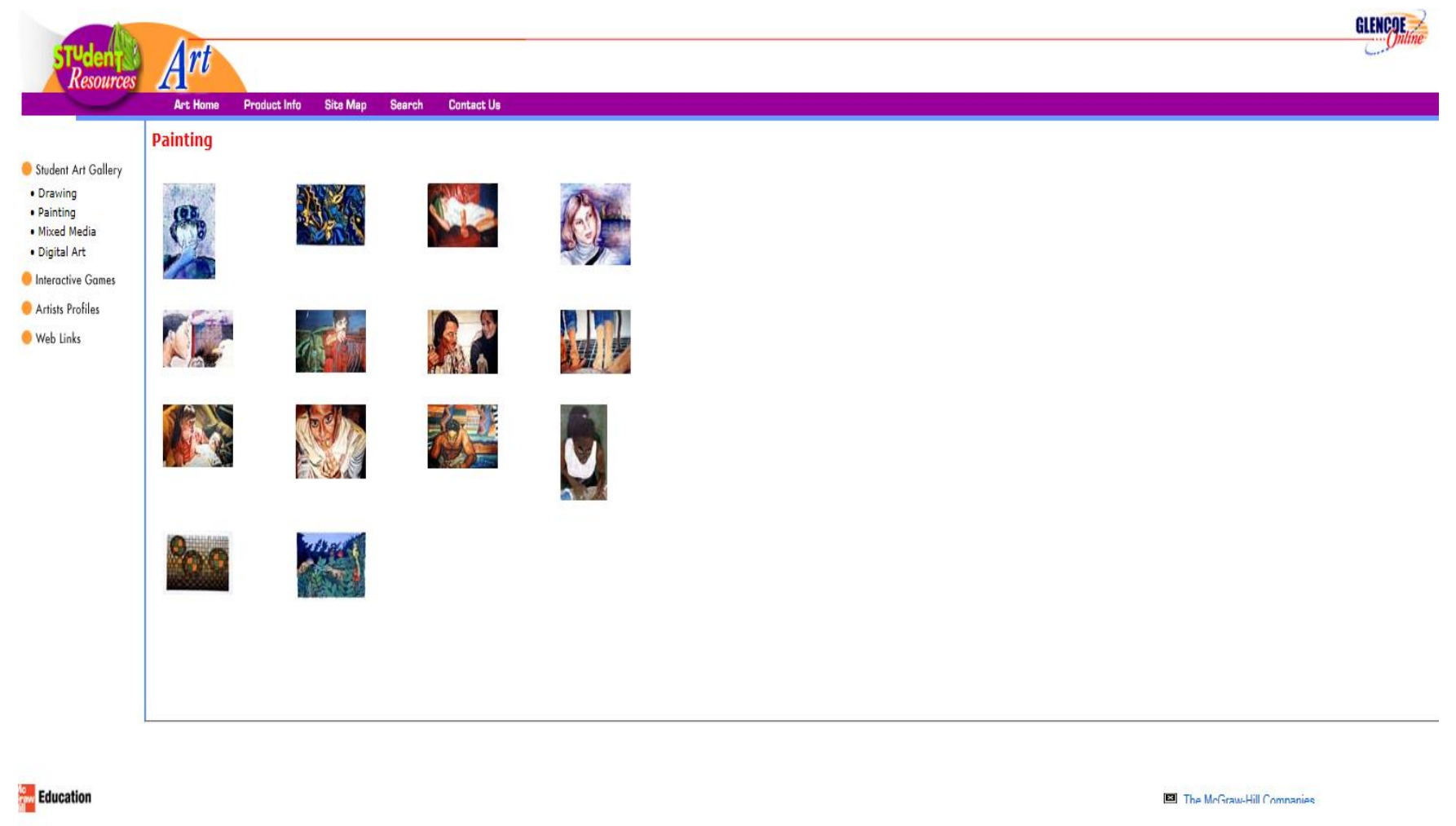

Figure 10: Student work on McGraw-Hill@ Online Art Gallery, specifically the painting section.

The artwork included information such as the title of the piece, first name of the artist, the name of the art teacher, art medium in which the student chose to work and the school the student attends (Figure 11). The sections included thumbnail images of the artworks. To view a larger image of the artwork, along with the specific information about the artwork, you clicked on the image that you wanted to view. 


\title{
Painting
}

\author{
Elephant Time \\ Student Artist: Azure \\ Teacher: \\ School: Roswell High School, \\ Roswell, GA
}

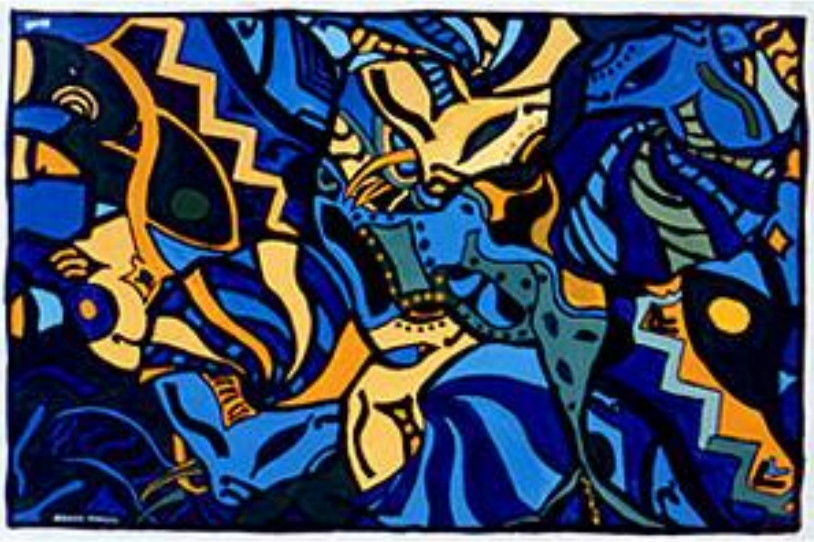

Figure 11: Student painting example with featured information, including the title and school of the artist.

Other features of the website included interactive games to help students learn about different art periods and artists. There was a link to artist profiles that presented a few paragraphs about several well-known artists. Information about the artists included their place of origin, what media the artist worked in, what art period the artist was involved in, and work inspirations (Figure 12). 


\begin{abstract}
Artists Profiles
Vincent van Gogh

Holland, 1853-90

Vincent van Gogh (van goh) was born at Groot-Zundret, Holland. He had begun drawing while he was a missionary, and in 1880 he finally decided to devote himself to his art. His early paintings, including such subjects as landscapes and peasants, were rather dark and subdued. Then, in early 1886, van Gogh discovered the Japanese Ukiyo-e (meaning "pictures of the floating world") woodblock prints, including those of Utagawa (Ando) Hiroshige. The Japanese print influence could be seen in his use of a slightly altered perspective, his placement of subject matter, and his flat shapes.

Another great influence on van Gogh was Impressionism. His brother Theo, an art dealer, introduced van Gogh to the work of Impressionists such as Monet and Seurat, whose pointillist technique involved placing points or dabs of pure color next to each other to be "mixed" in the eye of the viewer. Van Gogh's painting style is called PostImpressionist because his work followed the earlier period and was an effort to go beyond it. His colors grew much brighter, and his brushstrokes began to resemble many single active lines of color.

Though he was greatly troubled by seizures and depression in the last decade of his life, van Gogh's faith remained. In his landscapes and portraits, he painted both the seen and the unseen, the spiritual forces of nature. When he ended his life at age 37 , this genius left the world with 1,600 remarkable artworks.
\end{abstract}

Figure 12: Example artist profile with biographical information.

Finally there were additional web links to museum websites, technique websites, art history websites, and art of the Renaissance time period.

\title{
b. Mission Renaissance®
}

Mission Renaissance ${ }^{\circledR}$ was a website that catered to kids, teens, and adults. They had a chain of studios that offered classes to artists of all ages. These studios were based mainly in the state of California. Mission Renaissance ${ }^{\circledR}$ offered art camps throughout the year (spring, winter, summer). This website had three distinct online galleries for kids, teens, and adults. 


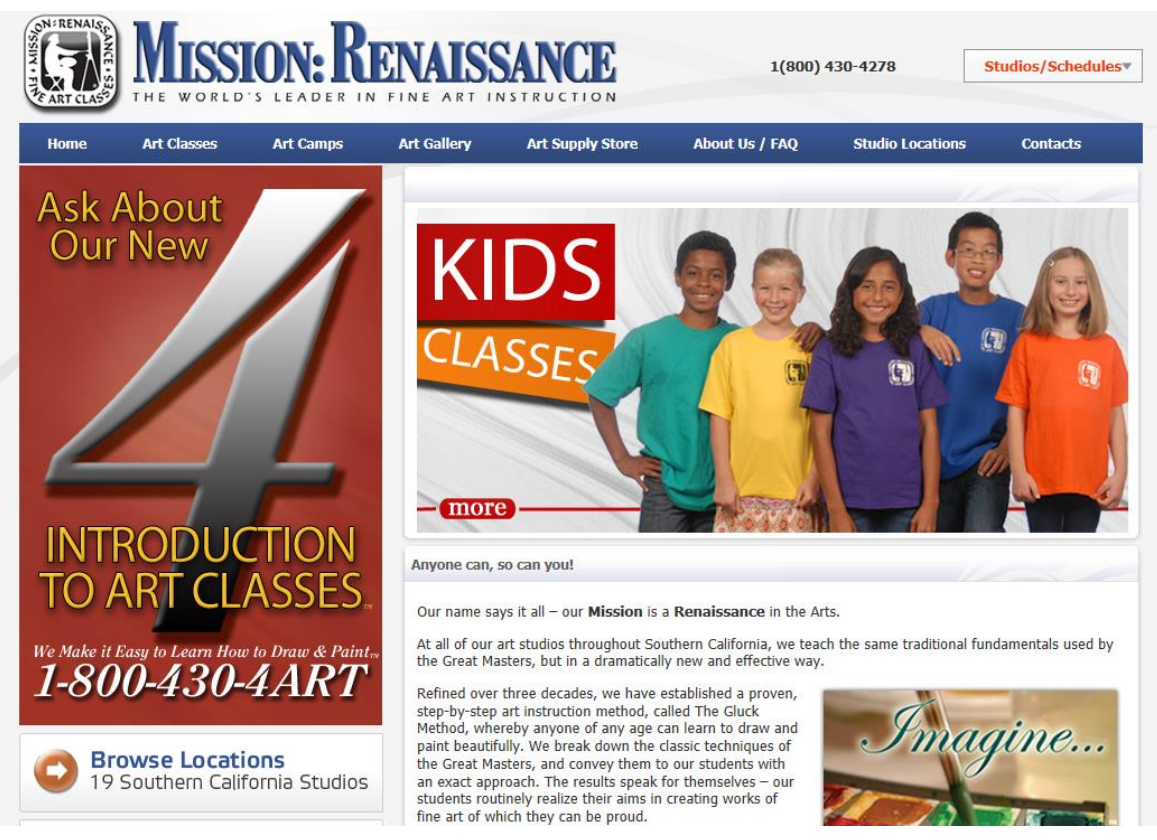

Figure 13: Home page of Mission: Renaissance ${ }^{\circledR}$ website.

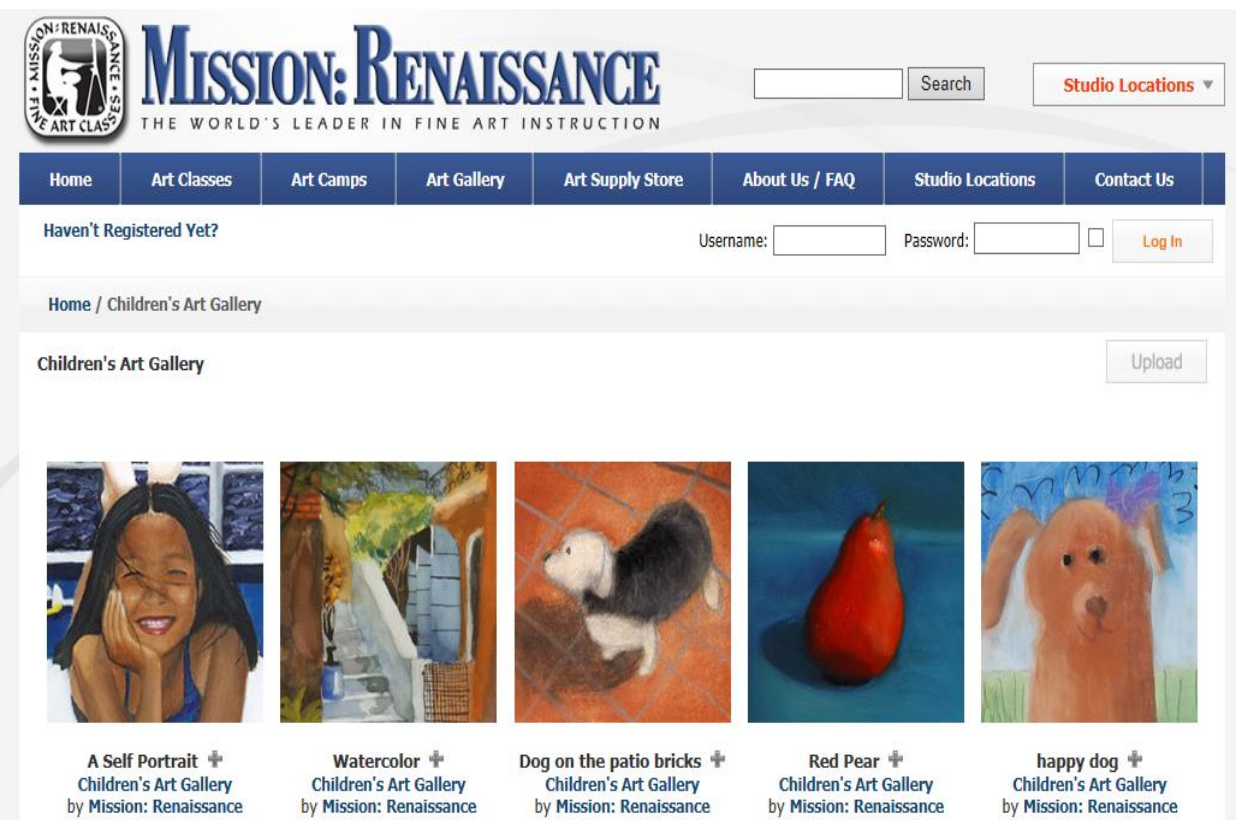

Figure 14: Student artwork featured on the Mission: Renaissance® website. 
The Mission: Renaissance® galleries mainly focused on painting, but occasionally featured drawings. Paintings included oil, watercolor, and acrylic. The subject matters covered still life set ups, landscapes, portraits, and more.

\section{a. The Natural Child Project $(\mathcal{C}$}

The Natural Child Project@ $\subseteq$ was aimed at parents with children or those interested in having children. They strove to provide information on parenting and early childhood development. They encouraged the displaying of children's art as a way to instill pride.

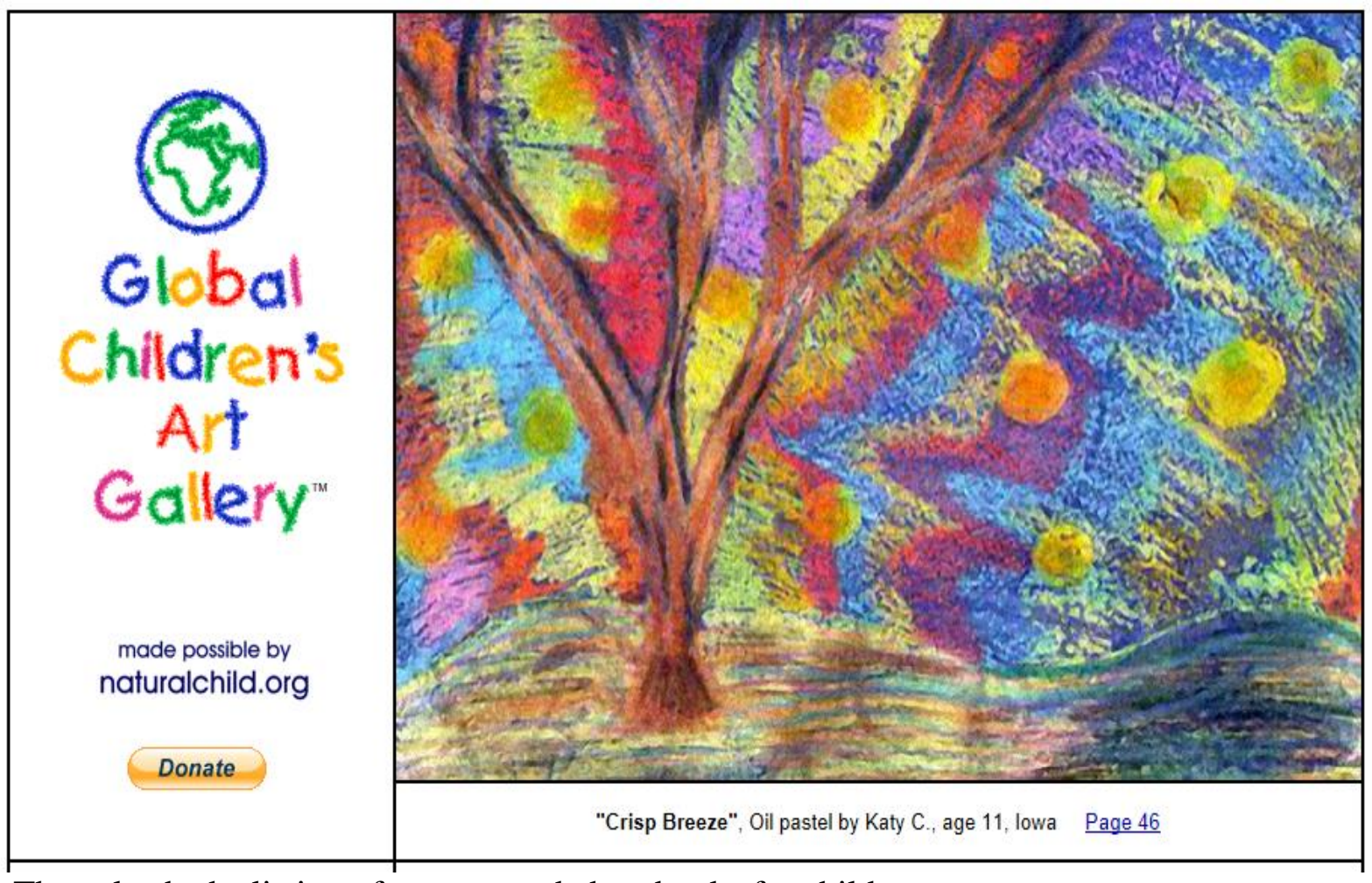

They also had a listing of recommended art books for children.

Figure 15: Student artwork and gallery homepage of naturalchild.org 


\section{Summary}

As previously stated, all of these websites offered opportunities for getting student art out onto the World Wide Web for more viewers. However, the websites did not have the global impact that Artsonia had gained. These were smaller sites that were still developing, acquiring more viewers and needing more artwork to display. These sites could be used as artistic tools for classroom learning and development. They offered their own unique features and aimed at particular audiences including children and parents. 


\section{Chapter Five}

\section{Findings and Conclusions}

\section{Description of the study}

I was interested in the use of online art galleries to display student (k-12) artwork, specifically the website, www.artsonia.com. I wanted to study a sample of up to 17 teachers who completed art related projects with their students. These teachers were asked to participate in a workshop at the John D. Rockefeller IV Career Center, specifically the TOC computer lab. During this workshop participants completed two short surveys, created an Artsonia account, learned how to photograph their students' works, and uploaded it to their Artsonia account. My main questions were to learn why teachers were not using online galleries to display student work and if they found Artsonia an easy site to utilize.

\section{Limitations}

When constructing this study I came across several limitations and I believed many could be remedied. The limitations applied to the small scale study as well as to a larger study, if a large scale study was conducted. Possible biases and blind spots I have thought about with this study were:

- The teacher's experience with and knowledge of technology. Some teachers may have felt overwhelmed by the use of technology or lack 
of experience with using technology since it was still a fairly new tool, therefore they (the teacher) avoided using online galleries to display work.

- Some art educators or other educators may have preferred displaying art in person either for personal beliefs or that they felt a piece of art was better experienced first- hand. Three-dimensional projects were harder to display online because they have more than one angle in which the project can be viewed. Detail within a project could be lost if photographed at a distance or photographed with a lower quality camera. Photographed paintings lose subtle textures that were visible when viewed up close. These reasons may have rested on the mind of the teacher and therefore hindered their decision to choose a traditional display method over a digital display method.

- The sample of teachers used for the survey questions. I only used teachers who signed up for the research study workshop. There could have been other teachers who have impressive student projects but did not sign up for the workshop.

- A lack of creative projects assigned to students by their teachers. Many educators have had to cut back on projects because they have to prepare students for testing. Many schools have lost funding if test scores were below a certain limit. Additionally, teachers could have had a deficiency of supplies to make any projects. 
- A lack of advanced technology within a school may have affected the decision to display projects digitally. Not every school had up- todate technology or technology capable of what the online websites required. This could have been due to an absence or decline of funding to the school system.

- The location of the school that was trying to display work digitally (if project was national). If a school was located in an extremely rural or isolated area, they might not have had internet availability. A school could be situated in a very art supportive community with many locations available to display artwork hence the teacher may not have felt a need to display work online at all.

- The viewing of artwork by random individuals may have impacted the decision to display work. Parents or students may not want work put out onto the World Wide Web either because of privacy issues, worries about online predators, or not wanting their work to be criticized by others. Many parents signed a form at the initial start of the school year, but not every parent signed the form allowing for their children's work to go online. Other times a student may not have wanted their work seen by others for fear of criticism, especially if the website allowed for comments.

- There were some difficulties with more than one teacher being a member of Artsonia that were from a single school. Additional teachers had to be verified through a fax sent from Artsonia. This fax 
was sent to the registered school for the teacher that needed verified. I have had to verify a second time, even though I was the first teacher to establish an account with the website.

\section{Summary of Findings}

\section{Pre-workshop Survey}

- $25 \%$ of the participants had viewed websites that were used as online art galleries.

- $75 \%$ of the participants had to think of a creative way to display their students' works because of a lack of traditional display space.

- $75 \%$ of the participants felt that they encountered obstacles when trying to display student work.

- $75 \%$ of the participants felt that their student's work had been hard to display because of its size, weight, or fragility.

- $75 \%$ of the participants felt that they did not have adequate display space.

- $50 \%$ of the participants shared display space with other faculty members of their school.

- $100 \%$ of the participants felt that it was important to display student work.

- $75 \%$ of the participants felt their students had access to technology. 
- $0 \%$ of the participants have had someone bring up the use of online art galleries to display their student's work (previous to the workshop).

- $75 \%$ of the participants were high school teachers and $25 \%$ were middle school teachers.

- When asked why they were not using online art galleries, $25 \%$ said they had never heard of online art galleries while $75 \%$ listed other as their reason.

\section{Exit Survey}

- $100 \%$ of the participants felt that their school had the necessary technological equipment to display art online if they chose to do So.

- $100 \%$ of the participant's students had access to laptop stations and computer labs.

- $75 \%$ had never seen a website that promoted student artwork.

- $75 \%$ of the participants felt that this method (online art gallery) was easier to use than a traditional method to display student work. The remaining $25 \%$ felt that the online method was about the same in terms of time spent setting up and effort put towards photographing the work versus laying out the gallery as the traditional display method.

- $100 \%$ felt that the workshop was helpful. 
- $100 \%$ of the participants said they would use this method of display again.

Findings from the surveys rendered the following information:

- Most participants felt that their school had the proper technological tools to allow the use of online art galleries and their students had access to computers (either laptop or desktop). One teacher specifically worked in a computer lab, several teachers had access to lap top stations, while the remaining teachers felt it was easier to schedule a visit to the school's computer lab.

- Most of the participants felt that posting artwork on an online art gallery was simpler than hanging or setting up work in a display case.

- Most participants had difficulty displaying student work traditionally either because of a lack of space, sharing space with other faculty members, or difficulty with the artwork itself. One teacher cited that she had problems getting the keys to a display case from another teacher.

- All participants felt that it was important to display student work, that the workshop was helpful, and that they would use online art galleries again to display student work. 
Participants were asked to expand upon their answers in the surveys. The following were comments, trends, and conclusions drawn from those responses. Most participants were not aware of nor had viewed online galleries until they attended the research workshop held at JDRCC. When asked if they had ever had to get creative with displaying projects, one participant described how they had to attach hooks to the ceiling of their classroom then string twine between the hooks. After all of the twine is strung, the projects, in this case, icosahedrons are strung from the twine with paper clips. Another participant had to tape artwork to long sheets of paper then staple the paper to a bulletin board in the hallway. She used this method because of the school's restriction of using tape on the walls. This same participant felt she had limited bulletin board space and not enough appropriate space to display three- dimensional artwork. Display space for participants was shared with multiple faculty members. One participant found it difficult to gain access to display areas (which are shared among approximately 40 staff members) and noted that the display cases were not very large so only a limited number of projects could be put in the case.

Similar to conclusions in the literature, participants felt that student work should be displayed to support student academic efforts. One participant responded with, "They get a chance to shine in a different area than academics. Some were good at both (art and academics), but others were not." Another comment from a participant was, "I also believe it gets students excited about art and hopefully it inspires them to be creative on their own work as well." 
Participants all noted that they had access to computer labs. One educator's class took place in a computer lab. However, the participant was frustrated over the fact there were few computers that were able to send to color printers. Another participant explained that it was difficult to schedule trips to the computer lab because of testing and core curriculum teachers got first bids on time slots for the lab. Participants were pleased that the website was introduced step by step and found the instructions easy to follow. They were also satisfied with the written instructions since some felt they would not remember all of the steps. No member had ever visited Artsonia, but felt it was a useful educational tool. Several participants noted that the school should become more involved with this particular website.

\section{Implications for Art Education}

This method of art display freed teachers from previous display restrictions such as shared display space between faculty members, limited time to display artwork such as in when displaying a show, vandalism to student artwork, and limits on materials that could be used to hang artwork. This method could be easier for teachers who have arthritis or other health problems in which moving around physically was more difficult. Teachers did not have to lift heavy objects or worry about falling from a ladder to hang art in high places. Temporary outdoor sculptures could be viewed for a longer period of time before the environment changed the piece. Changes to the 
outdoor sculpture could be recorded and posted to show the progression of the artwork and the affects that nature can have on an art piece.

Using online art galleries could give students more power in choosing what artwork they wanted to display and the descriptions that they wanted to be included with their artwork. Artsonia gave the option of allowing students direct access to edit their work on the chosen gallery. Students were able to add artist statements, giving insight into their thought process when they were making their work or what their inspirations were for creating it.

I felt it was inspirational for students to see what other students their age were making. One of the participants in the study commented that their students enjoyed seeing work created by other students at a similar age level and viewing this work could make project results appear more attainable versus a project example created by an art teacher who had taken years of classes and had much more experience. Students could create their own accounts and browse the website or purchase items with their work on it. Parents of students could create fan clubs to support students.

\section{Implications for Education and Specialized Fields}

I felt that this was a wonderful opportunity for specialized educators outside of art to get creative with projects and collaborate with other educators, not just create projects with art educators. Numerous teachers have had their students create interesting projects but did not have the display space available. Educators could gain new ideas from the 
lesson plan element of Artsonia which featured a wide array of class subject choices. Using an online art gallery could help teachers meet certain content standards dealing with both incorporation of the arts into their classroom and integration of technology within their lesson plans.

\section{Recommendations for West Virginia Art Education}

I recommend that as many schools as possible within West Virginia become members of the Artsonia website. Becoming a member could be a way to have collaborative galleries between schools throughout the state and share project ideas. There could be collaborations between West Virginia colleges or businesses and Artsonia for additional galleries. With this website teachers could submit their students' works online instead of shipping it directly to the source of the show. Parents would not have to travel two- three hours to view their child's artwork. They could simply access it on the website.

Additionally, at a smaller scale, I wanted to attempt and get the Hancock County Board of Education to include a direct link to Artsonia on the Hancock County Education website, making it easier for interested viewers to find the website. The Hancock County Website provided information such as board meeting agendas, new job opportunities, school cancellations, and links to online grade books. I wanted to add another opportunity to get student 
artwork into the community besides the few art shows that are offered in the tri-state area.

\section{Recommendations for Further Study (ies)}

I recommend a larger study be conducted, either by having a large workshop (such as a conference) with many teachers, sending out an email to the art educators of WV to encourage membership, or by having several small workshops around the state. This conference could possibly be supported by the West Virginia Department of Education for all general and specialized educators interested in the website, not just art educators. More data could be collected and analyzed to narrow reasons why this online tool is not being utilized more frequently and if the educators using the site in fact found it to be easier than traditional gallery and exhibition methods.

Another study could have involved finding schools that are in different parts of the United States and having teachers do a collaborative project. One teacher could have their students create a project preferably two-dimensional, and then send it digitally to another teacher. The other teacher could then have their students manipulate the projects to create something new or express their reaction to the original work. The second teacher could then post the new work in a gallery created on Artsonia for the other initial teacher's students to see what became of their artwork. 
Sending the artwork digitally both incorporates technology into learning as well as reduce costs that would develop from mailing the artwork. In conclusion, data suggested that teachers may not use the websites because they had never been introduced or viewed examples, but found the website easy to navigate after introduction and explanation. Reading and data provided evidence that educators and students alike thought artwork should be viewed for emotional, psychological, and art education advocating purposes.

\section{Bibliography}

Balsley, J. (2013). The Real Deal: How three Teachers Use Artsonia in their Classrooms, The Art of Eduction.

Burton, David (2010). Web-Based Student Art Galleries. Art Education, Vol. 63, No. 1, 47-52.

Efland, A. (2002). Art and cognition. New York, NY: Teachers College.

Coates, M. (2009). Howard County (MD) Public School District. Retrieved May 1, 2013, from http://www.hcpss.org/arts/visularts/gallery_high.shtml

Emerson R.M., Fritz R.I., and Shaw L.L. (2011), Writing Ethnographic Field notes, Second Edition.

Freedman, K. (2003). The importance of student artistic production in teaching visual culture. Art Education, Vol. 56, No. 2, 38-42. 
Johnson, J.B. (2009). South Highlands ES, Shreveport, LA. Retrieved May 2, 2013, from http://teacherweb.com/LA/SouthHighlandsElementary/ArtDepartment

Katz G. (1993). What can we learn from Reggio Emilia? In Kim H., Park E., and Lee J.(2001), “All Done! Take it home” Then into a Trashcan?: Displaying and Using Children's Art Projects. Early Childhood Education Journal, Vol. 29, No.1.

Kieling, I. (2009). Rosemont Ridge Middle School, West Linn MS. Retrieved May 2, 2013, from http://www.rrms.wlwv.k12.or.us

Kim H., Park E., and Lee J.(2001), “All Done! Take it home” Then into a Trashcan?: Displaying and Using Children's Art Projects. Early Childhood Education Journal, Vol. 29, No.1.

Kvale S.and Brinkmann S. (2009), Interviews: Learning the Craft of Qualitative Research Interviewing, Second Edition.

Leekeenan D., and Nimmo J. (1993). Connections: Using the project approach with 2- and 3- year olds in a university Laboratory School. In Kim H., Park E., and Lee J.(2001), “All Done! Take it home” Then into a Trashcan?: Displaying and Using Children's Art Projects. Early Childhood Education Journal, Vol. 29, No.1.

Lu, L.F. (2013) 3D Virtual Worlds as Art Media and Exhibition Arenas: Students' Responses and Challenges in Contemporary Art Education. 
Studies in Art Education. A Journal of Issues and Research, Vol. 54, No.3, 232-245.

Marshall, J., \& Vashe, M. (2008). Mining, bridging, and making: Developing and conveying concepts in art. Art Education, Vol. 61, No. 1, 6-12.

Merriam-Webster. (2005) Merriam Webster; New edition Collegiate Dictionary, Eleventh Edition.

Moniques R. and Suzanne L. (2001). "School Art Exhibitions, Critical and Reflective Approaches.” Student Art Exhibitions: New Ideas and Approaches, National Art Education Association.

Prescott, L. (2009). Rexburg ID. Retrieved May 2, 2013, from http://mms.d321.k12.id.us/webart/index.html

Robbins, S., \& Bell, M. (2008). Second Life for dummies. Hoboken, NJ: Wiley.

Seefeldt C. (2002) Creating Rooms of Wonder: Valuing and Displaying Children's Work to Enhance the Learning Process.

Shannon, M. (2009). Mitchell, MS and Mitchell Senior HS Mitchell SD. Retrieved May 2, 2013

Wilke, W. (2009). Crete Public Schools, Milford NE. Retrieved May 2, 2009, from www.creteschools.com, Go to Middle School; Art 


\title{
Appendix A
}

\section{Letter of Permission}

\author{
HANCOCK COUNTY SCHOOLS \\ Wayne Neely. Assistant Superintendent \\ wneely@access $k 12$ wr. us

To: West Virginia University KC

Fm: Wayne Neely. Assistant Superintendent W//

Re: Elissa Dray Research

Elissa Dray will be conducting research at the John D. Rockefeller IV Career Center during an upcoming class. Mr. Marty Hudek, Director of the John D. Rockefeller Career Center, is aware that research will be conducted on the premises; she has Hancock County's permission to conduct such research.

The eamera which will be given away by "random draw" (by placing participants name on a slip of paper, placed in a container and then drawn by a participant) was purchased for the amount of \$89.99. The funding source is the Technology Department of Hancock County Schools; the cost incurred will be taken from the Technology Department. The participant whose name is drawn will sign a waiver acknowledging the camera to be the property of Hancock County Schools; this equipment will be used for educational purposes only and will be kept at the school.

If you have any further concerns or questions, please contact my office. Thank you.

CC Marty Hudek

Elissa Dray 


\title{
Appendix B
}

\author{
Research Study Advertisement
}

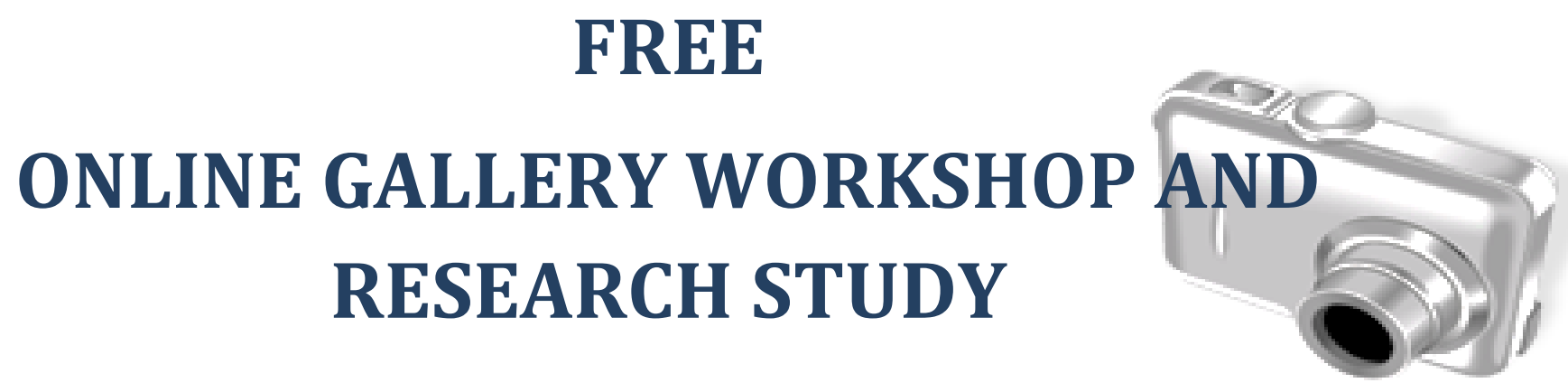

ELIGIBLE PARTICPANTS:

DATE:

TIME:

LOCATION:

DESCRIPTION:

REGISTRATION:

FEE:
Professional Staff Only

Spring Trimester

4:45pm - 7:00pm : 2 hours, 15 minutes

John D. Rockefeller Career Center TOC Lab

This class is open to all general education teachers Grades K-12 who complete art related projects with their students (such as having them illustrate a story or sculpt, but not limited to those media). This class will demonstrate how to photograph and upload their student's work, plus create an Artsonia LLC account.

This class will be limited to the first $\mathbf{1 7}$ teachers who register on the Professional Staff

Development Website (Class \#00366). Participants will also be required to complete the online evaluation afterwards.

There is no fee for this class. Two digital cameras will be given away at the end of the class. No stipends will be paid. 
Participants are to bring what they use to take pictures, needed USB cords to transfer photos, and one or two examples of a project their students have completed. Memory card readers are NOT available.

QUESTIONS:

Email Elissa Dray at hdray@access.k12.wv.us

Ronald Aman at

Ronald.Aman@mail.wvu.edu

WVU IRB approval is on file 


\section{Appendix C}

\section{Instructions for Creating an Artsonia Account}

To get started with setting up a teacher account, go to the website www.Artsonia.com. This step also applies to anyone wanting to make a parent account.

An Artsonia account is free of charge to join for teachers, parents, and students. Teachers will be able to create and manage student artwork exhibits, along with communicate with parents who wish the join Artsonia to view their child's work. Parents are able to purchase products with their child's art features on it. They are also able to form fan clubs for a particular school.

\section{To create a teacher account:}

At the top of the webpage beside the Artsonia logo, it reads "Art Museum”, “Gift Shop”, “Teachers", "Parents”, “Blog”, click on the “Teachers" option (Figure 16). 


just beyond imagination Art Museum Gift Shop Teachers Parents Blog enter search text

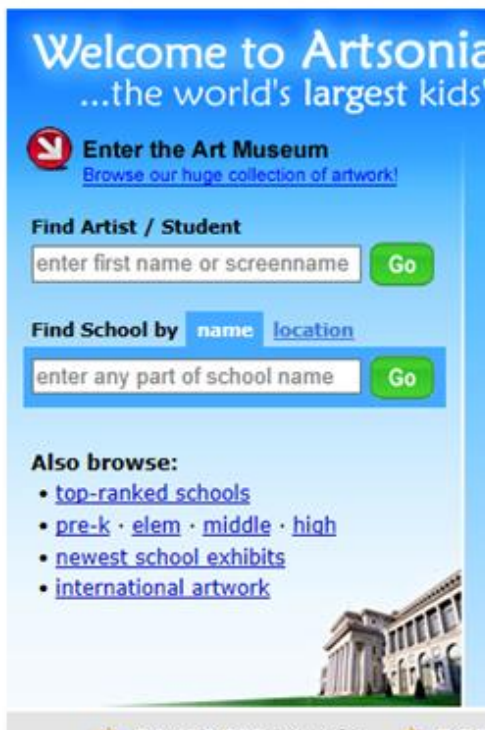

\section{年}

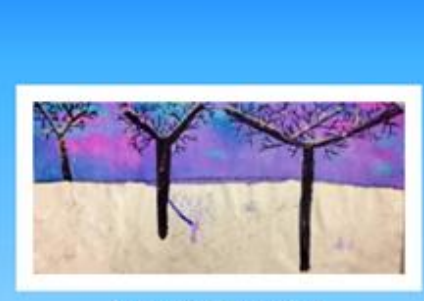

by Emma5917, grade 3 Hillcrest Chnstian Lower Elementary School

\section{$24,496,922$ artworks}

$2,844,380$ added this school year! 19,563 added yesterday!

\section{Artist of the Week}

Vote on weekly winners!

This week's finalists...
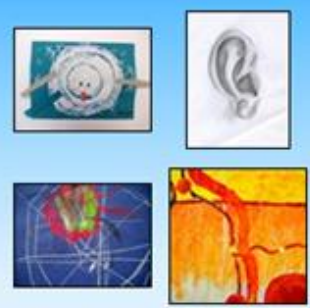

Vote on All Finalists!

24, 296,922 artworks

$3,387,637$ artists

4,289,014 fanclub members

$\mathbf{8 4 , 7 5 9}$ teachers

5,062 lesson plans

What is Artsonia?

Artsonia is the largest student art museum in the world! Every child can have an online art gallery and preserve their masterpieces for all time

Learn more

Watch our Video Introduction
Follow Artsonia!

Stay connected to

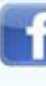

Thanks to our Supporting Partners!

\section{BLICK: National}

art materials NaeA Art Education

\section{News \& Events}

Artsonia iPhone/iPad app version 2.2.2 available We've made a few more enhancements to our mobile app for iPhones and iPads, now available in the AppStore.

NAEA National Art Education Association Convention Teachers - meet Artsonia in March 29-31, 2014 at the NAEA National Art Education Association Convention in San Diego.

Figure 16: Home page of www.artsonia.com

Towards the bottom of the teacher's page, it reads "Create a New Account" or "Login", click "Create a New Account". Eventually after your account is created you will select, "Login" (Figure 17). 


\section{artsonia \\ Art Museum Gift Shop Teachers Parents Blog}

just beyond imagination

Welcome | Signup for FREE Account | Lesson Planning

\section{Welcome, Teachers!}

Artsonia is the world's largest kids art museum online. It's the newest way to celebrate creativity in the classroom and get families involved in art education!

Kids develop a new sense of pride and feel like famous artists published in a museum!

Family and friends view the artwork, join fan clubs and leave personal comments for the artists.

Schools earn $\mathbf{2 0} \%$ when parents purchase custom keepsakes with their child's artwork - a great fundraiser for your arts program!

Thousands of Art Project Lesson Plans have been submitted by teachers just like you, and are available as a resource for your classroom!

(2) Tell me more about how this works

\section{Participation is always FREE! \\ Join the THOUSANDS of teachers who've discovered how EASY it is to publish artwork!}

Figure 17: Screen shot of initial steps to create an Artsonia account

The next webpage asks where your school is located, select "My school is based in the United States (US)" then click continue (Figure 18). If your school is not based in the United States of America, please choose the appropriate country. 


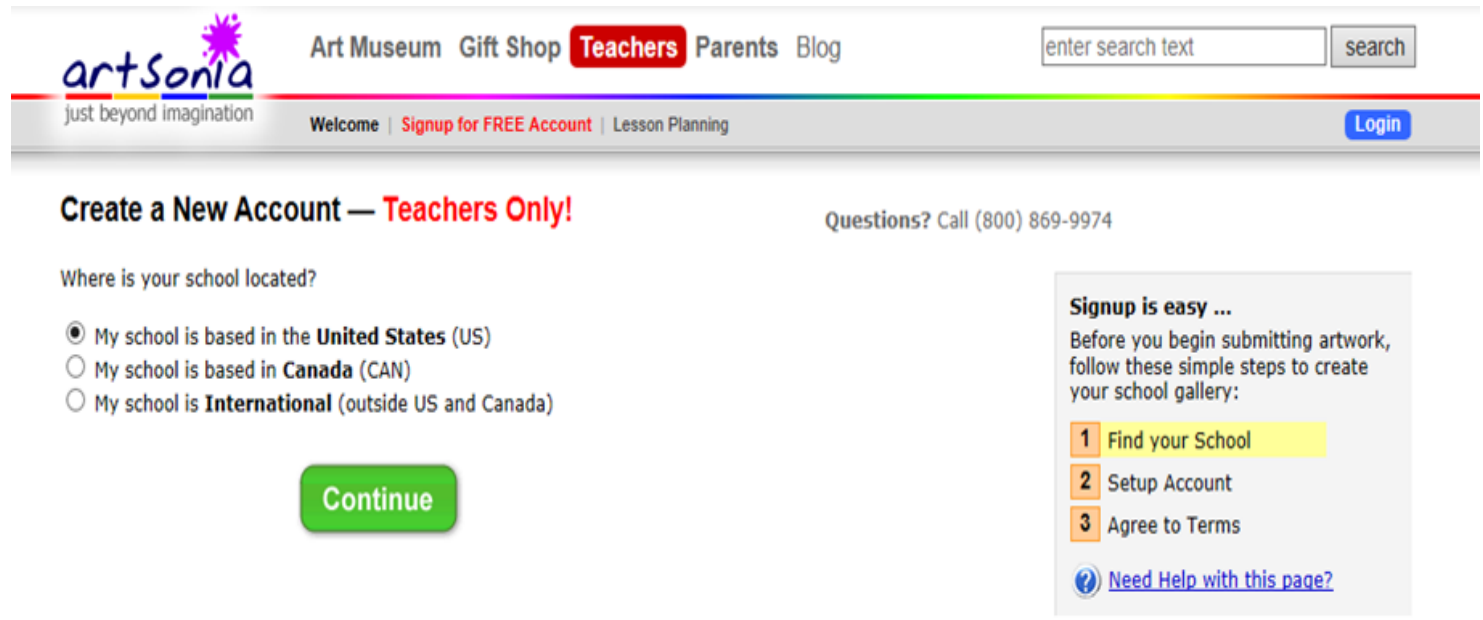

Figure 18: Screen shot with the selections of the country choices available

To locate your school, type your zip code or city/state into the text box. In this case I will put 26047, the zip code for New Cumberland, West Virginia, then click continue (Figure 19).

Four selections appear when this zip code is entered:

- John D. Rockefeller Vo-Tech Center

Rr 2 Box 138A, New Cumberland, WV

- New Manchester Elementary School

Rr 3 Box 3400, New Cumberland, WV 
- Oak Glen High School

Rr 1 Box 422A, New Cumberland, WV

- Help! My school isn't listed above!

(Select this option to fill out your school address.)

*Oak Glen Middle School is still listed as 26034, Chester, West Virginia, along with Allen T. Allison Elementary.

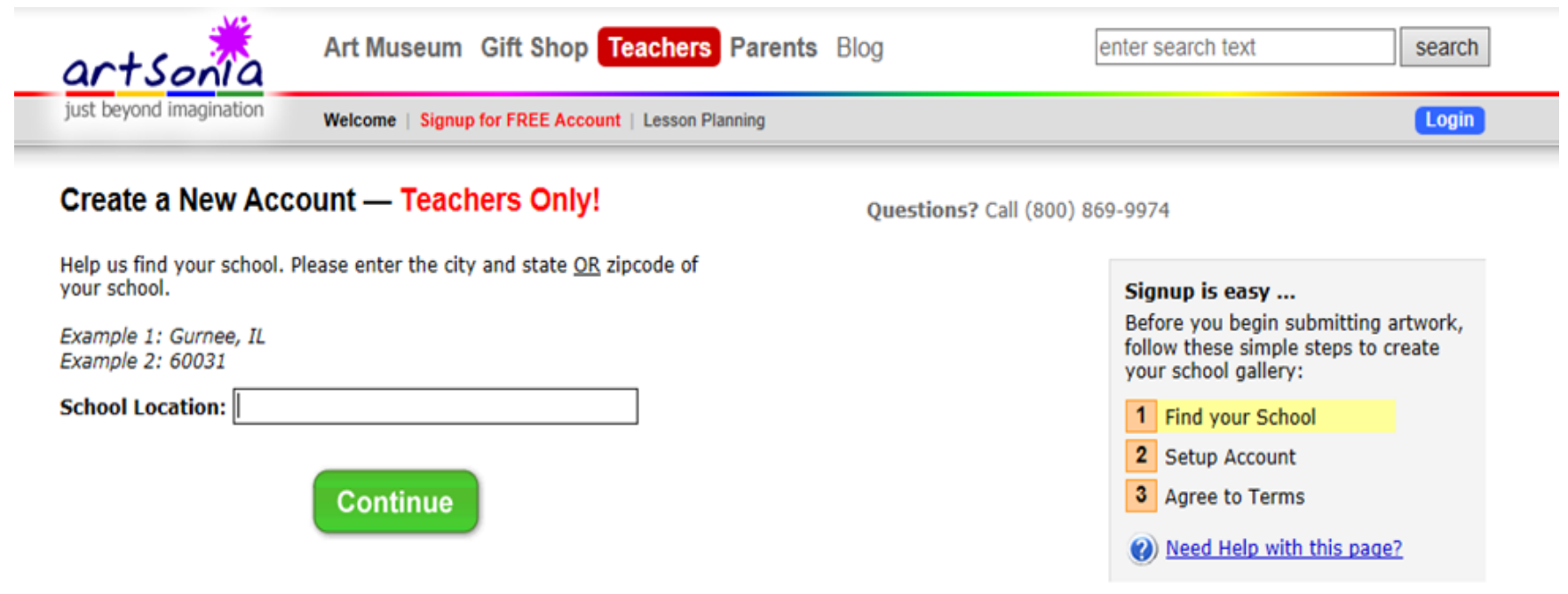

Figure 19: Screen shot displaying the step for finding a teacher's participating school

Select the school that you are currently teaching at, I will select Oak Glen High School, then click continue. To create your teacher account, you will 
need to input your appropriate information for each blank. Information includes: first name, last name, email, and a created password of your choosing. After all the information is filled in correctly click the continue button (Figure 20). I recommend that you use your email assigned by your school system. I initially tried to use my yahoo email account and the information would not go through. For the second attempt I used my school email address and the information successfully submitted.

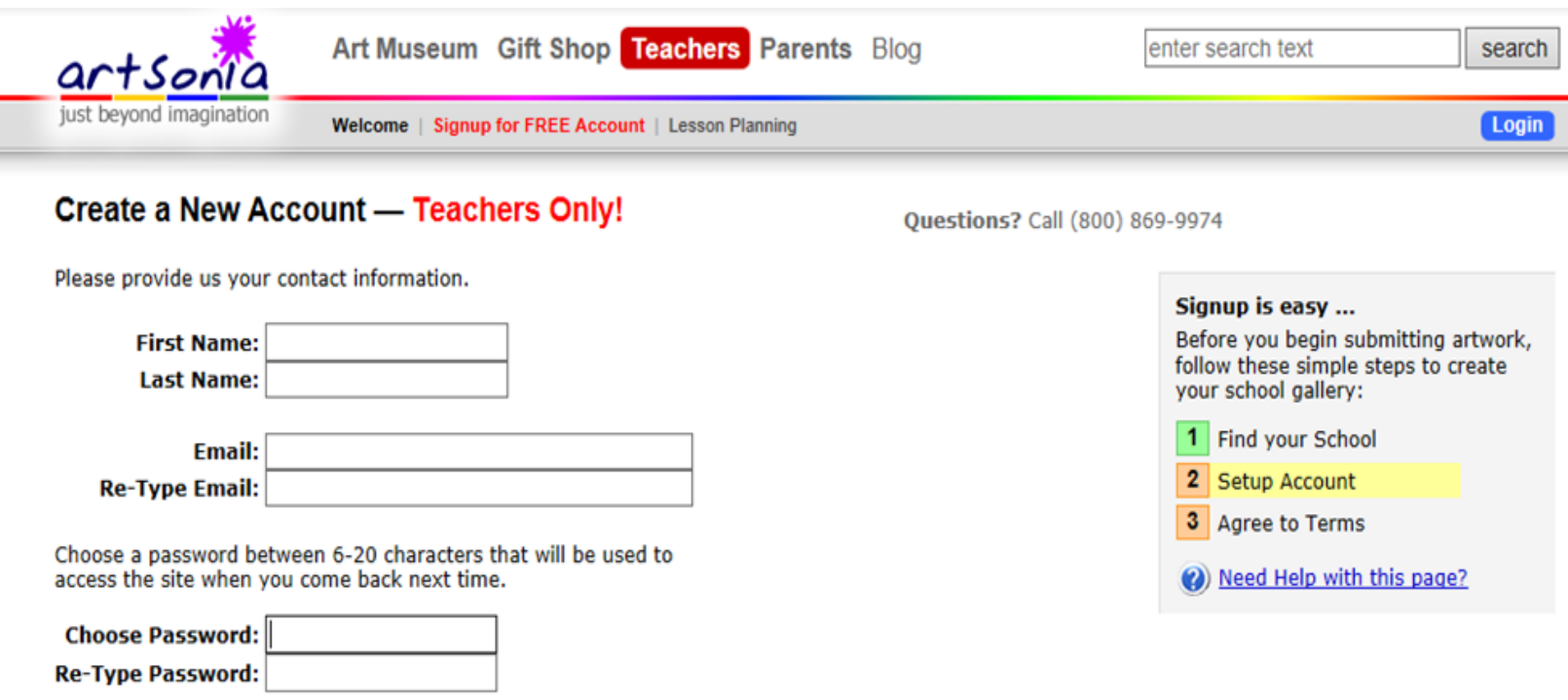

\section{Continue}

Figure 20: Screen shot of page that requires a teacher's name and email

The next page explains Artsonia's policies on security. They ask that the following measures be taken: 
Below are a few recommendations we ask our teachers to follow:

- Avoid publishing any artwork that contains photos of the child.

- Avoid publishing any artwork that has the child's last name visibly written on the artwork itself. To help visitors find the artists, Artsonia gives each child a unique "screen name", which is usually the first name and a unique number.

- Do not publish any artwork with nudity or extreme violence. Artsonia caters to all grades, so a little prudence is appreciated.

- Each published artist will be assigned a "security key" - a short code of letters and numbers - that is needed for the artists' parent to register and approve comments. Please do not give this security key to strangers.

I have avoided posting any artwork that has images of the student's in it at all. This included: self-portraits, collages, or even pictures of the student holding their own project. If you agree to all of the privacy terms, click check the box that says, "I agree to use the Artsonia Art Museum in accordance with the Terms \& Conditions of Use" then click continue (Figure 21). 
We take privacy and security very seriously here at Artsonia. With millions of artwork published from thousands of schools around the world, you can rest assured that we provide many safeguards for our young artists.

Below are a few recommendations we ask our teachers to follow:

- Avoid publishing any artwork that contains photos of the child.

- Avoid publishing any artwork that has the child's last name visibly written on the artwork itself. To help visitors find the artists, Artsonia gives each child a unique "screenname", which is usually the first name and a unique number.

- Do not publish any artwork with nudity or extreme violence. Artsonia caters to all grades, so a little prudence is appreciated.

- Each published artist will be assigned a "security key" - a short code of letters and numbers - that is needed for the artists' parent to register and approve comments. Please do not give this security key to strangers.

Please check the following box to continue:

I agree to use the Artsonia Art Museum in accordance with the Terms \& Conditions of Use.

\section{Continue}

\author{
Signup is easy ... \\ Before you begin submitting artwork, \\ follow these simple steps to create \\ your school gallery: \\ 1 Find your School \\ 2 Setup Account \\ 3 Agree to Terms \\ (2) Need Help with this page?
}

Figure 21: Screen shot of Artsonia's privacy terms and conditions. As displayed, Artsonia takes privacy of student artwork seriously to protect website users from unwanted viewers.

\section{SECUREA}

\section{ThA ENCRMPIED}

ns network
Artsonia is a safe \& secure website

Figure 22: Screen shot of security encryption displayed on Artsonia's webpage 
Occasionally the privacy terms and conditions change. An email will be sent out to Artsonia users notifying them of any current changes of these changes.

Congratulations, you are now a member of Artsonia! Your Artsonia teacher account user name will now be presented on the computer screen (Figure 23). I advise that you write down both your username and password in case you forget. Please place this information somewhere that you will not easily lose it.

- We've assigned you a unique "username" based on the information you've entered (see below).

- Next time you return to Artsonia.com, you will need this username and your password to login to your account.

- We have sent you a confirmation email containing your username and password. Please keep it safe.

Username:

Password: (not shown for security, you provided this earlier)

You're now ready to submit artwork or view lesson plans! Click the Continue button to access your new account.

\section{Continue}

Figure 23: Screen shot of a successful teacher account creation. Please remember to record your password and username in a safe location. 
You are now free to add students, lesson plans, create your teacher biography, and add security questions to help you remember your password. You have access to all of the features on your account page and can begin establishing your own student portfolios and exhibits (Figure 24). A yellow box at the top of the screen brings attention to items that need taken care of immediately (Figure 25).

Welcome, Elissa Dray from Oak Glen Hiah School

\begin{tabular}{|cl|}
\hline My School Gallery - Build it Here! \\
\hline 1 & $\begin{array}{l}\text { Setup Student Roster } \\
\text { Setup your online student roster. }\end{array}$ \\
\hline 2 & $\begin{array}{l}\text { Get Parent Permission } \\
\text { Get and track parent permissions. }\end{array}$ \\
\hline 3 & $\begin{array}{l}\text { Setup Artwork Exhibits } \\
\text { Organize artwork and artist statements. }\end{array}$ \\
\hline 4 & $\begin{array}{l}\text { Upload Artwork } \\
\text { Get your artwork up on the site. }\end{array}$ \\
\hline 5 & $\begin{array}{l}\text { Create Parent Accounts } \\
\text { Get parents connected with your program. }\end{array}$ \\
\hline
\end{tabular}

\begin{tabular}{l} 
My Fundraising \\
Available Balance: $\$ 0.00$ \\
Review tips on successful fundraising \\
Redeem earnings at any time \\
$\begin{array}{l}\text { Rewards include iPads, Amazon.com Gift Cards }{ }^{+} \text {, art } \\
\text { supplies, cash and more! }\end{array}$ \\
\hline
\end{tabular}

\section{My School Activity}

my school gallery $\cdot \underline{\text { top West Virginia schools }}$

Rank Category (this year)

0 artworks

(i) $\mathbf{0}$ fanclub members

Q 0 comments

0 artist statements

\$0 funds earned *

is overall rank

Awards Earned (this year)

R 0 student awards

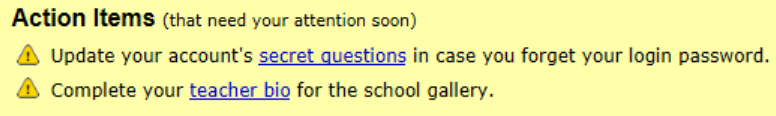

Action Items (that need your attention soon)

4. Update your account's secret questions in case you forget your login password.

1 Complete your teacher bio for the school gallery.

\section{Additional Activities}

Further enhance your Artsonia experience.

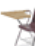

Classroom Mode NEW Learn how students can directly submit their artworks and statements.

Student Proaress Reports NEW Perform student assessments to illustrate growth. Share with parents!

Technology in the Art Room Learn how to use iPads, projectors and

Lesson Plannina Browse our collection of lesson plans, or submit your own

Art Room Newsletters Send out school-wide eNewsletters to students' parents.

2 Enhance My School Homepage Customize and add fun to your schoo Custemize and add
gallery homage.

Update My Teacher Account Update your name, email, password, photo and more.

Helpful Resources Tutorial videos, printable guides, and other useful documents.

Find Security Keys Quickly find security keys for parents who ask for them.

NAEA Membership Click to signup or add member \#. not a current member

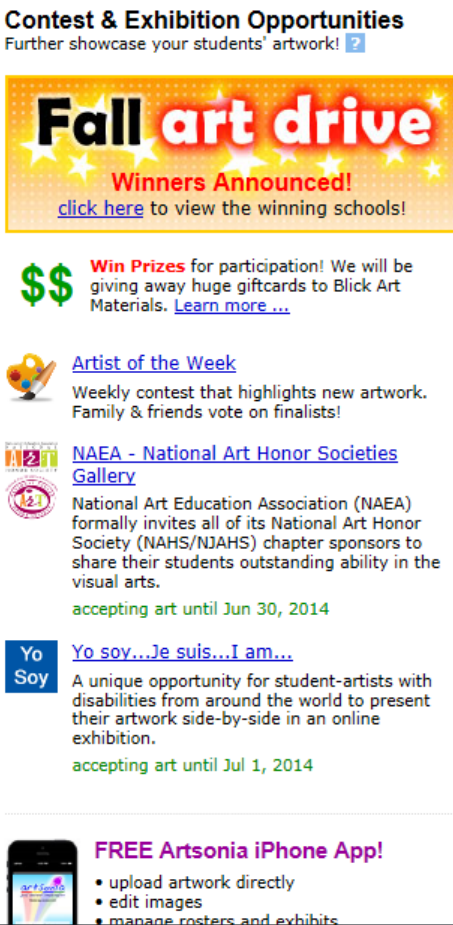

Contest \& Exhibition Opportunities Further showcase your students' artwork! ?

\section{Fall art difue}

Winners Announced! click here to view the winning schools

W. Win Prizes for participation! We will be giving away huge giftcards to Blick Art Materials. Learn more ...

Artist of the Week Weekly contest that highlights new artwork. Family \& friends vote on finalists

A12 NAEA - National Art Honor Societies Gallery

(12)

National Art Education Association (NAEA) National Art Education Association (NAEA)
formally invites all of its National Art Honor Society (NAHS/NJAHS) chapter sponsors to share their students outstanding ability in the visual arts.

accepting art until Jun 30, 2014

Yo soy....Je suis...I am..

A unique opportunity for student-artists with disabilities from around the world to present exhibition.

accepting art until Jul 1, 2014

FREE Artsonia iPhone App! - upload artwork directly - edit images

\section{P是 $\mathrm{x}$ 目}

Figure 24: Screen shot of Artsonia teacher account. This page displays all of the activity in the account. It also provides links to other areas of Artsonia including the lesson plan features, progress reports, and more.

To add your review questions, simply click on the highlighted blue phrase,

"secret questions". Next you enter your username and password. After you have entered 
that information, you will select two safety questions that will help in case you forget your user password. Once you have selected and answered your questions, the click the continue button.

\section{Action Items (that need your attention soon)}

4. Update your account's secret questions in case you forget your login password.

4 Complete your teacher bio for the school gallery.

Figure 25: Yellow alert action box that appears toward the top of the screen

After you have completed your secret questions, you can move on to your teacher biography. To start your biography, click on the blue phrase, "teacher bio". In your teacher biography you can include a brief paragraph about yourself and upload a picture if you wish to do so (Figure 26). Biographies range depending on the teacher. Some teachers use the entire space while others chose to include very little or nothing at all. 
Edit Teacher Bio:

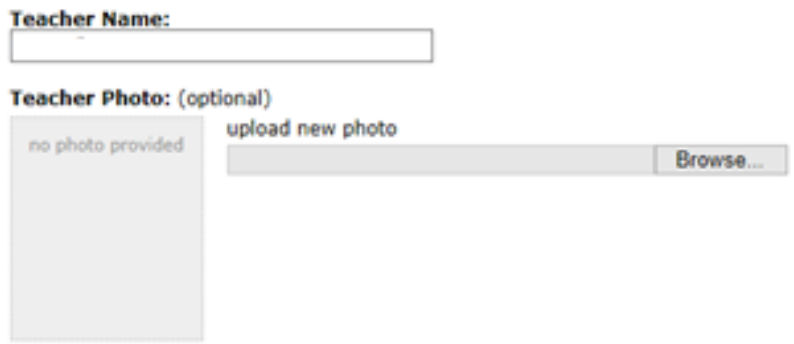

Teacher Bio (must be less than 5,000 characters)

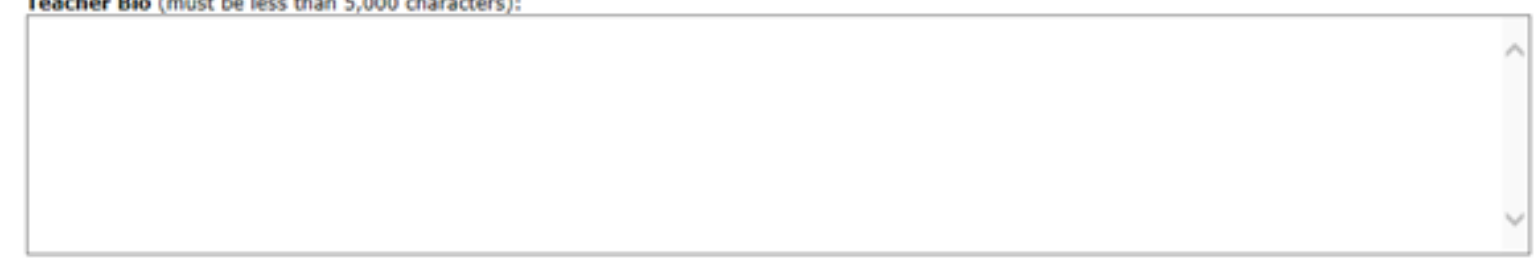

$\nabla$ show this teacher bio on the school gallery "meet the teachers" section

\section{$\checkmark$ Accept $Y$ Delete Cancel}

Figure 26: Screen shot of biography portion of Artsonia

When adding additional teachers to the same school they will not be confirmed automatically. A fax will be sent to the school to confirm that the teachers are instructors at that facility. If a fax is not received, simply send an email to Artsonia asking that the fax be resent or for the teachers to be confirmed.

\section{1) Uploading student artwork onto Artsonia}

To upload artwork:

On the top left side of the webpage in the green box, select 4 Upload Artwork 
You now have 2 options (Figure 27). You can choose to let students upload their own work, but choose the settings/review what they are uploading, or you can choose to upload the work yourself.

Upload Artworks
back to atact otas
Artworks can be added to the site in several different ways. Please choose the most appropriate for your classroom.
Option 1 - Allow students to submit their own artworks NEW
You may allow your students to directly contribute their artwork to your school gallery, Click the button below to review the access settings for each
exhibit. Students can be provided a special URt. and an access code to securely upload artwork. You will then have the opportunity to revilew these
artworks before they are published in the school gallery.
revicw access
You have not yet granted access to any exchibits.

\section{Option 2 - Upload your students' artworks on your own}

If you prefer to take digital photos of your students' artworks and upload them to the website on your own, click the button below, We prowide several built-in image uploaders as well as mobile apos for the iphone and ipad.

\section{ready to upload}

Figure 27: Screen shot of options showing who can upload the student artwork

If you want to upload photographs that you have taken of your student's work, select ready to upload. The next page displays a variety of ways that teachers are able to upload pictures (Figure 28). You may have to install a certain program if you wish to use it. In this case, I chose Flash Uploader. 


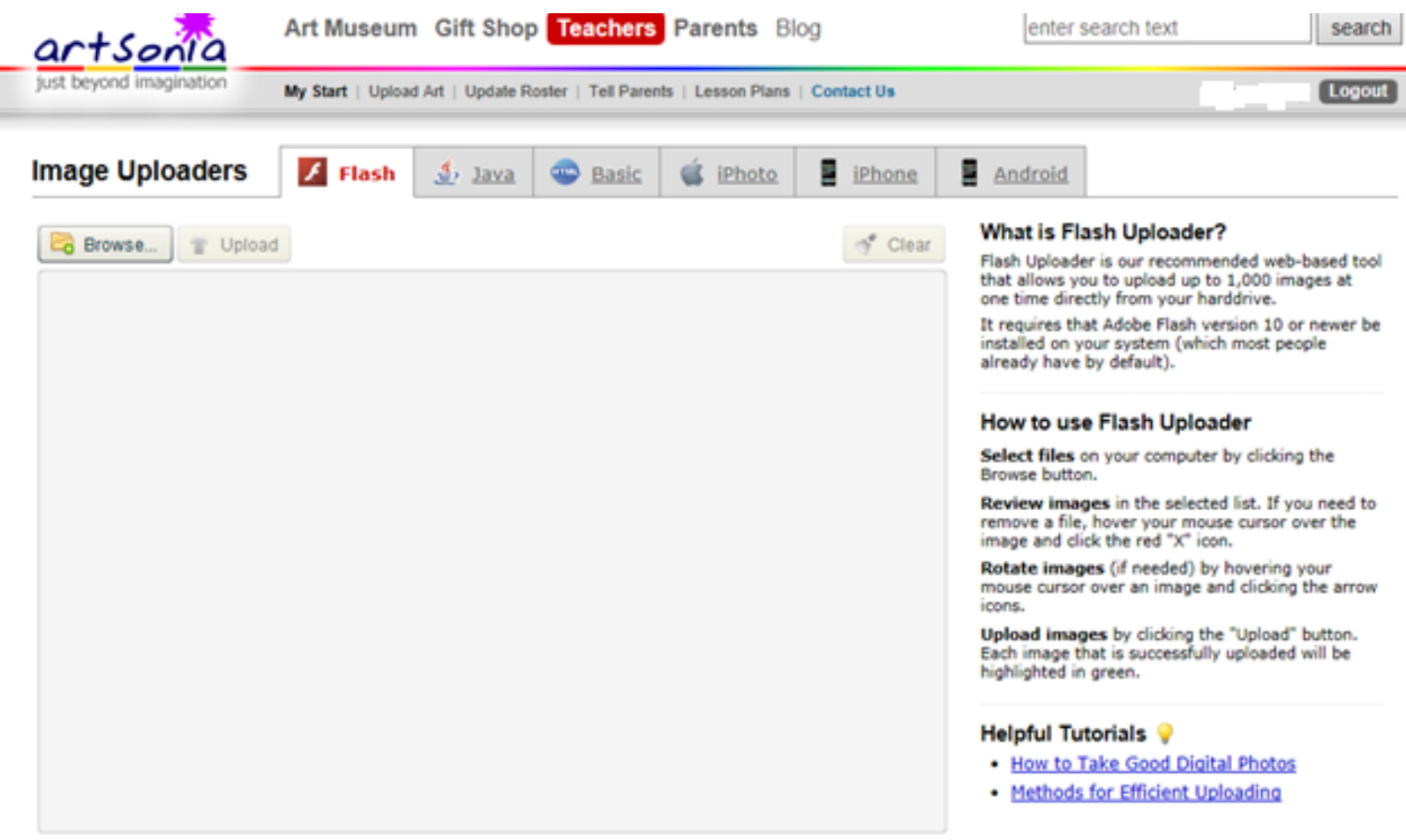

Figure 28: Screen shot of Artsonia.com page with the options to upload student artwork

You can email photographs of the artwork to yourself, select browse, and then select the work that you want to upload. This option allows you to choose more than one artwork at a time (Figure 29). 


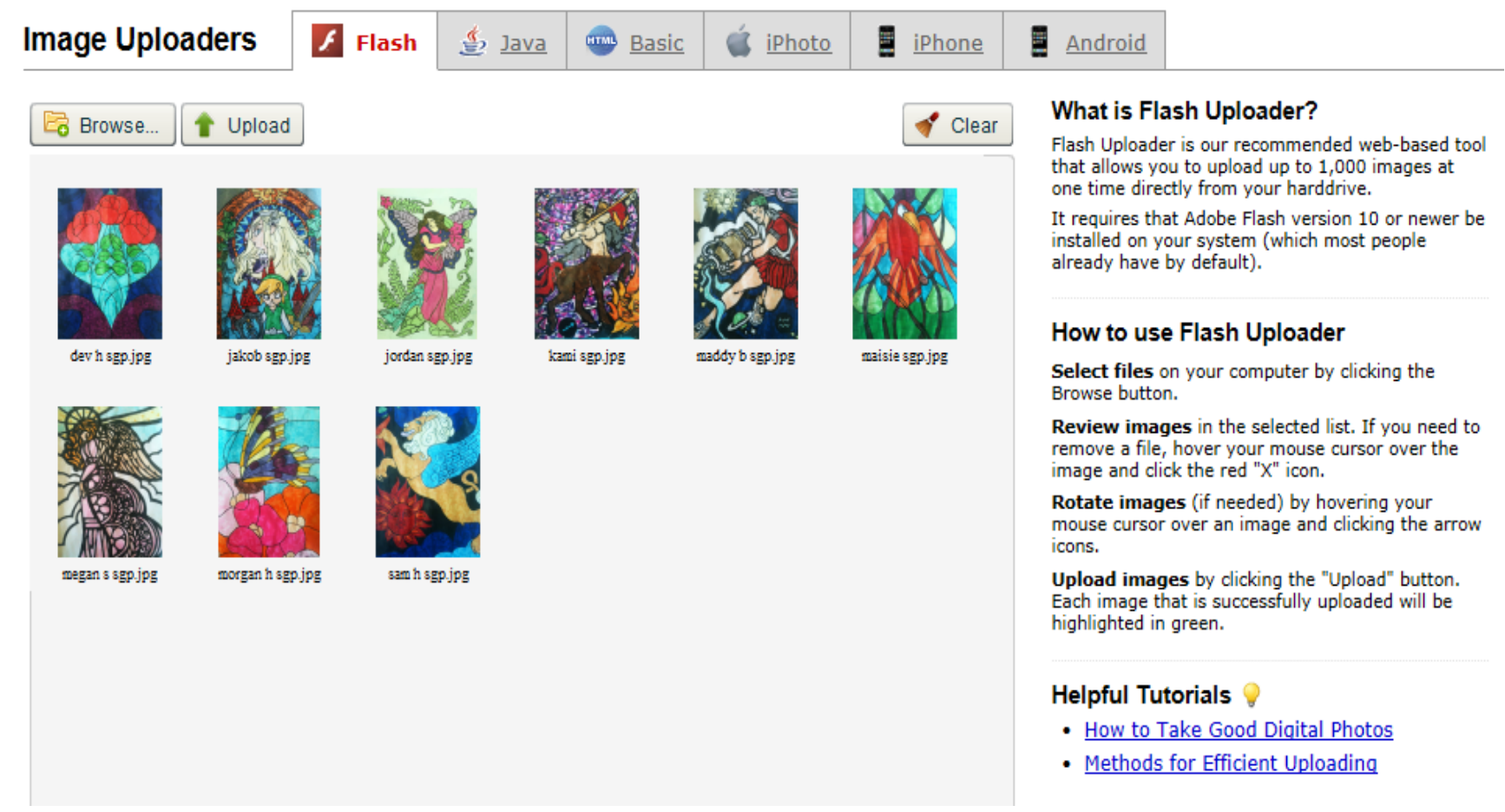

Figure 29: Screen shot example of multiple uploaded student art pieces

Once you have selected all of the art you wish to upload at that given time, click on the upload button with the green arrow. The art pieces will highlight in the order that they are uploading onto the site.

When artwork is uploaded, it will give the options of publishing right away, uploading more art without publishing, save the images without publishing, or delete all of the images (Figure 30). If you choose to publish the student work, a screen will come up asking about the first work that you uploaded. An option to create an exhibit will also appear on the screen under the grade of the artist. There is also the option of placing the title of the specific artwork and the student's artist statement. If all of the artwork you have published is within the same assignment and you wish to make it an exhibit, choose, 
"create exhibit". This option will allow you to name what the exhibit is, what media the projects were created in, list the teacher who taught the assignment, write a description of the assignment, and to upload a lesson plan that goes along with the exhibit (Figure 31).

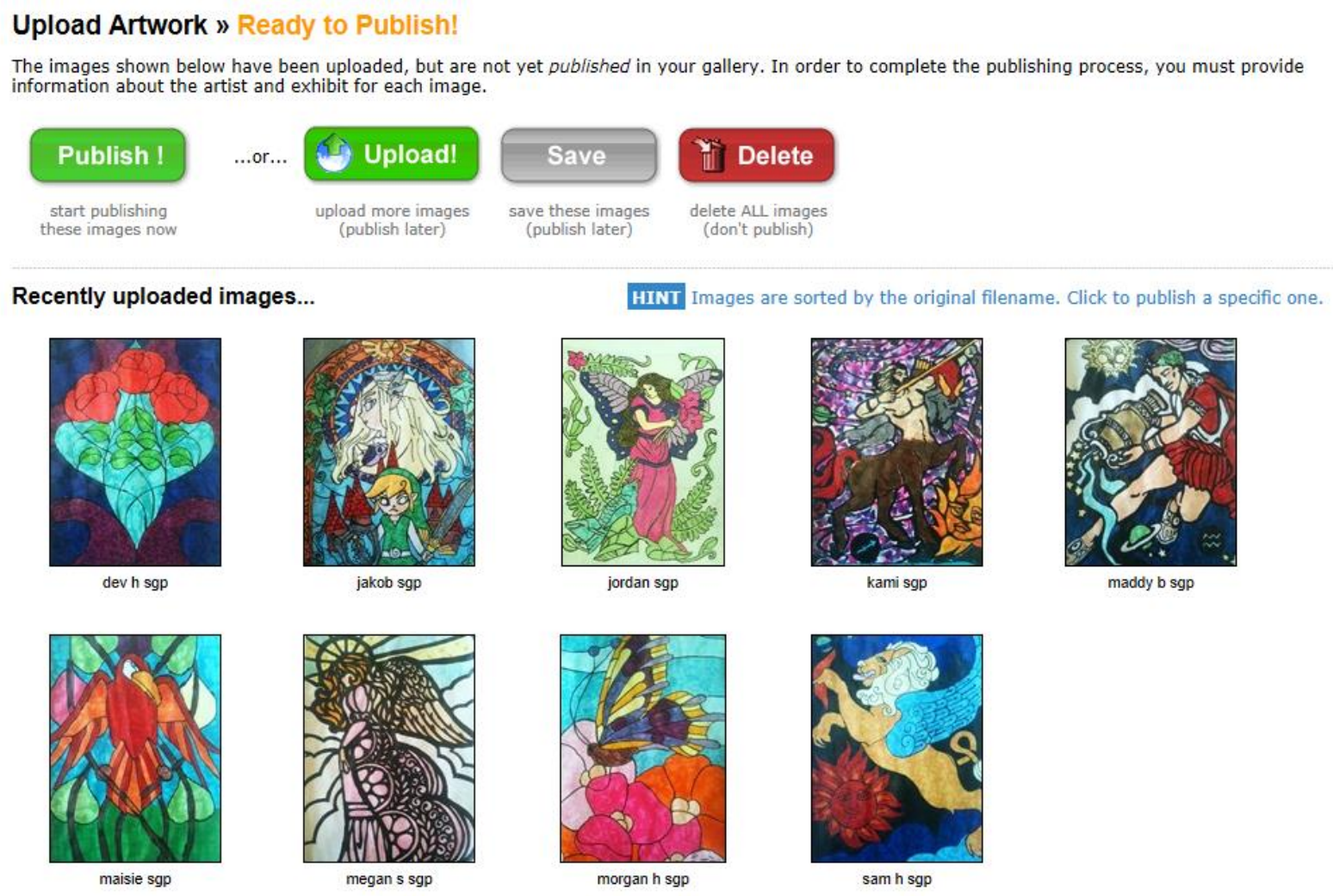

Figure 30: Student artwork uploaded, but not published to the website 


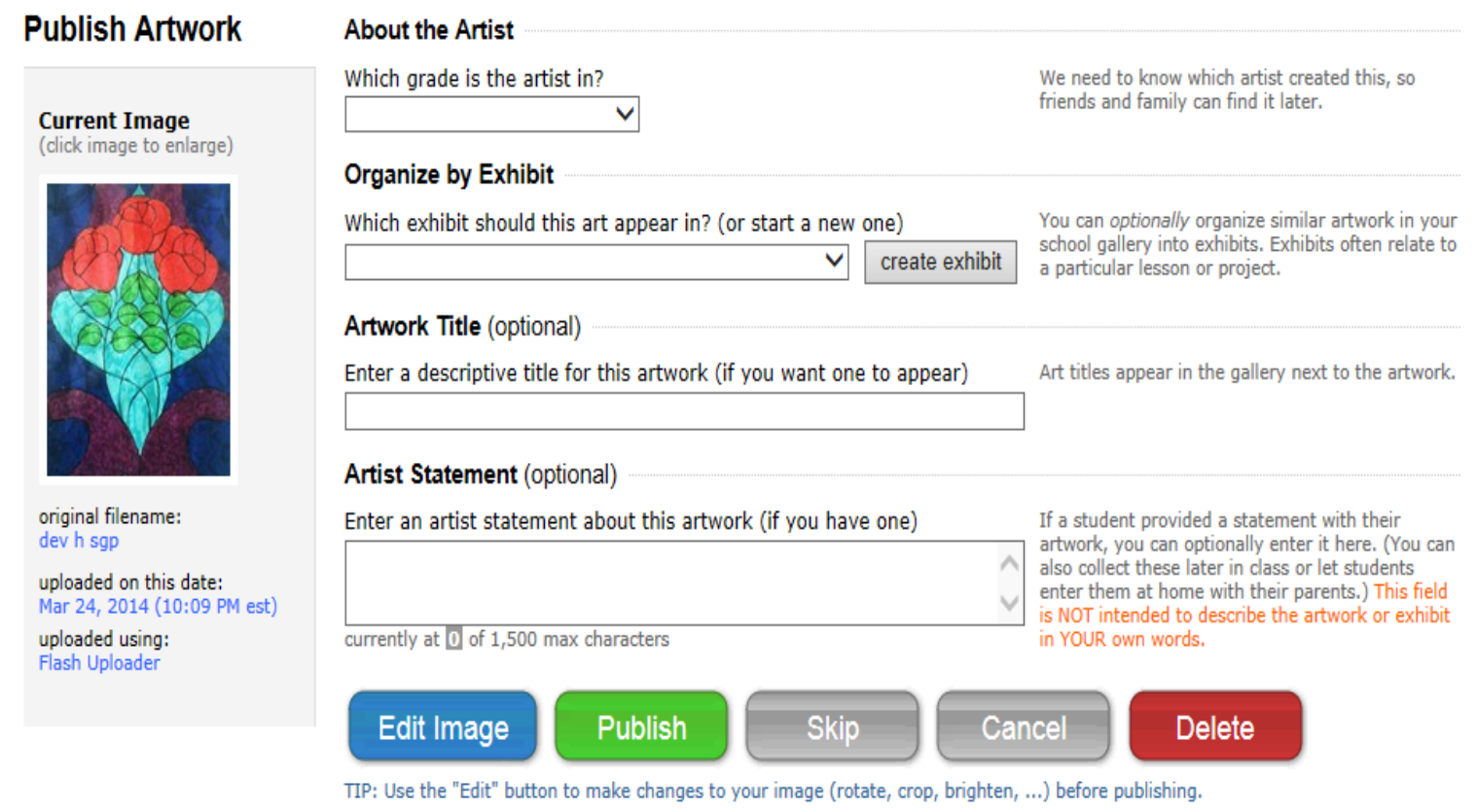

Figure 31: Screen shot after all artwork is uploaded but before an exhibit is created. This is where information such as the title of the artwork or the student who created it can be listed.

After you are finished creating the exhibit, you can then go through each individual piece of artwork and label which student created it, what grade the student is in, and choose the option that permission was granted for the artwork to be displayed online. After all information is appropriately filled for each artwork you can choose to publish the exhibit. After the initial submission, you can always go back and add more art pieces or edit information that may be incorrect (Figure 32). 


\section{Artwork Submission Complete}

You have completed the information for all submitted artwork.

What would you like to do next?

\section{(1) Upload!}

upload more images right now

\section{Back to Start}

go back to my start page

Figure 32: After an exhibit IS submitted, the above image appears giving you the option to return to your home page or upload more artwork.

If you choose to return to the home page, a notification will appear at the top of your home screen in the yellow box asking if you would like to enter parent emails or print out notification slips to send home with students (Figure 33).

\section{Action Items (that need your attention soon)}

441 students have artwork published by you this school year but no parent account has yet been created. You can enter parent emails or print take-home slips for these students.

Figure 33: Screen shot of notification for sending parent emails or print take home slips for students

If you want to send home notification slips, click on the words, "print take-home slips”. A new screen will appear with various options for the notification slips. Choose what you feel is appropriate for your situation (Figure 34). 


\section{Parent Slips: Request for Download}

back to start paqe

Before you generate the Parent Slips, please review your selections at the bottom of this page.

Which students do you want to include in these slips?

Include all students listed below.

Include only those students whose parent has not yet given permissions (those shown as "missing" under Permission).

(- Include only those students whose parent does not have an account created (those shown as "none" under Parent Acct).

Also include parents with emails entered that haven't yet activated their account (those shown as "pending" under Parent Acct).

Let me specifically choose which students to include (from the list below.)

\section{Continue Cancel}

Figure 34: Screen shot of options for parent notification slips

The next step is to choose which students will receive the slips. There are several options for selecting which students from the roster will have notification slips printed out (Figure 35).

\section{Student Summary}

Below is a list of all students that match the criteria you specified. It is organized by roster group (if applicable), then by grade, then by artist.

- ALL Roster Grades/Groups

- ALL Exhibits

- Students who published this school year

- Students who published artwork that only I submitted

\begin{tabular}{|c|c|c|c|c|c|c|}
\hline Name (ScreenName) & Roster Group & Grade & Last Art & Permission & Parent Acct & it Comments \\
\hline Cassidy (Cassidy3043) & - & 9 & $3 / 19 / 2014$ & granted & none & - \\
\hline Chase (Chase7401) & - & 9 & $3 / 19 / 2014$ & granted & none & - \\
\hline
\end{tabular}

Figure 35: Options for selecting students who would receive parent slips. I only included the first two students on my roster. 
After the students have been selected, a notification will be sent informing about the slips being processed (Figure 36). An email will be sent to inform when the slips are ready to be printed then passed out. The slips also inform parents about creating an account with Artsonia to view the artwork.

A Your requested slips are now being prepared and will be ready shortly.

The slips you requested are currently processing on our server. They will be available on this page for download in about a minute. You will receive notification via email as well as a message on your start page when the download is available. You can also just hang out on this page until they are ready.

\section{Parent Slips}

\section{back to start paqe}

Parent Slips are small pieces of paper that the students take home which give the parents activities to do with their child's artwork, such as setting up their parent account, approving comments, updating the student fan club and more. If the parent has not yet created their account, this slip will provide them with instructions (including the child's security key) on how to confirm they are the parent or legal guardian.

\section{request new slips}

\section{cancel}

Requested Documents

Date

$3 / 24 / 2014$ preparing slips

entire roster, published this year, just my students

Slips will be available for up to 7 days after their original request date. Don't worry, you can always request new ones at any time.

Figure 36: Notification that parent slips are being processed 


\section{Appendix D}

\section{Instructions for Creating a Light Box}

\section{Instructions on how to make a light box}

Not all schools have access to photographic equipment; this is a cheaper

alternative to purchasing a light box. I wanted a clean background in which to photograph 3-dimensional projects. This can also double as a lesson plan for a photography or art class.

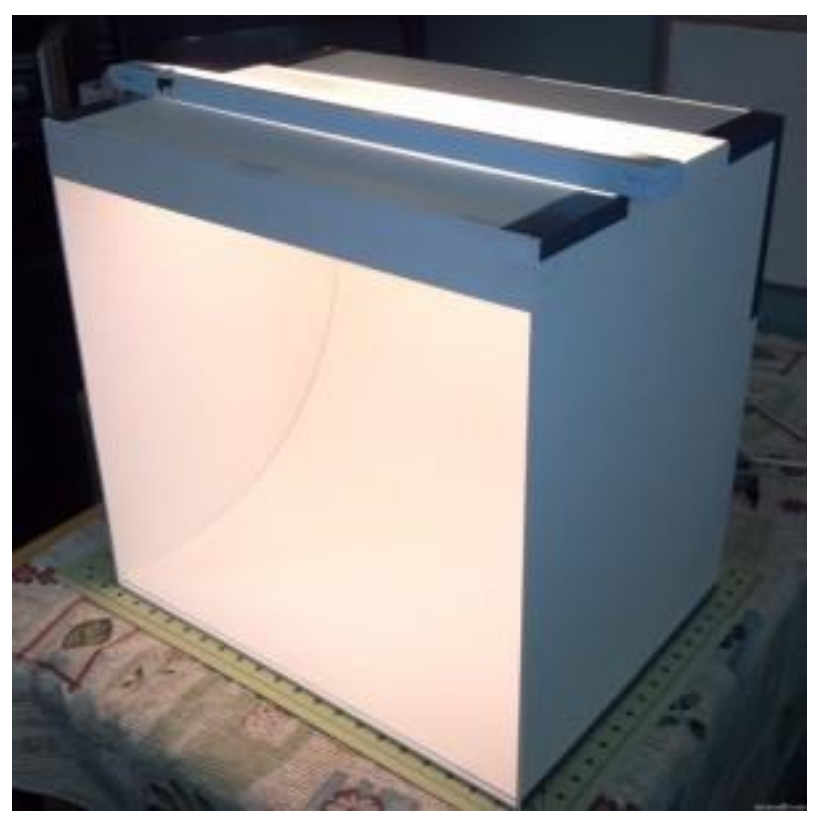

Figure 37: Fully constructed light box

Making a light box does not have to be expensive. The internet has plenty of ideas for light boxes. These all do the job just fine. The box itself is constructed from white 
foam board located at Wal-Mart. White poster board is used as the background of the light box.

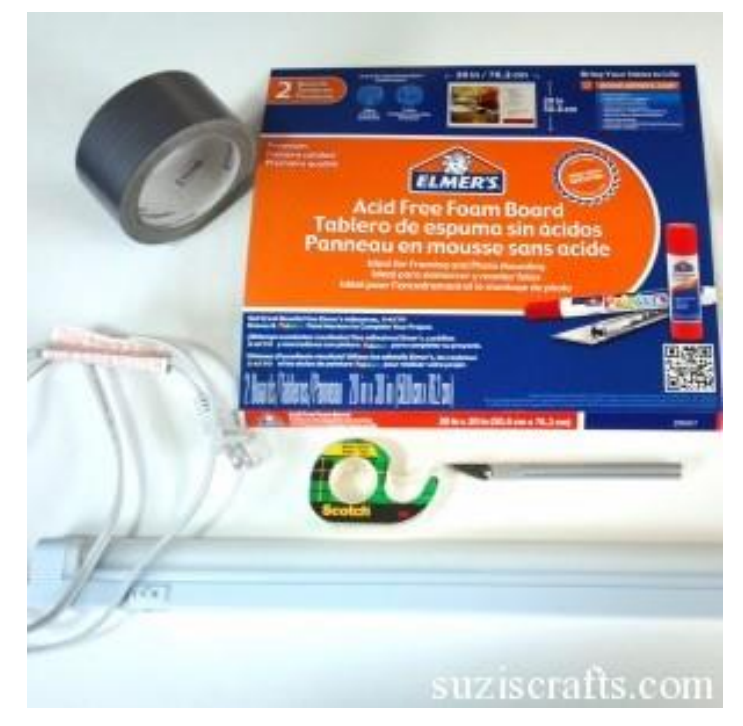

Figure 38: Pictures of materials used to create the light box

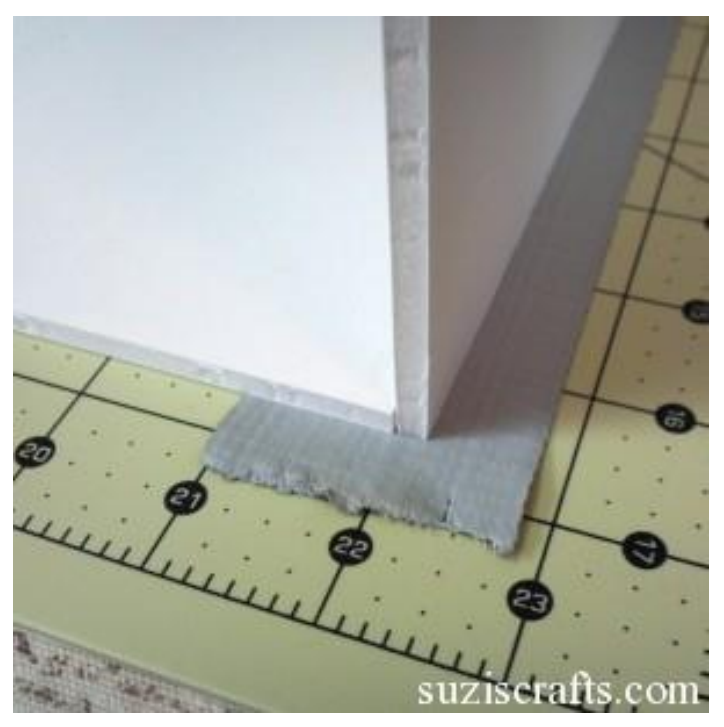

Figure 39: Method for lining up the edges of the light box

For the foam board, you get two $20 \times 30$ pieces. I cut them both in half to get four $15 \times 20$ pieces. Three pieces make up the sides and bottom. The fourth piece I cut into 3 
more pieces to support the top and back. All the pieces have been assembled together using regular duct tape.

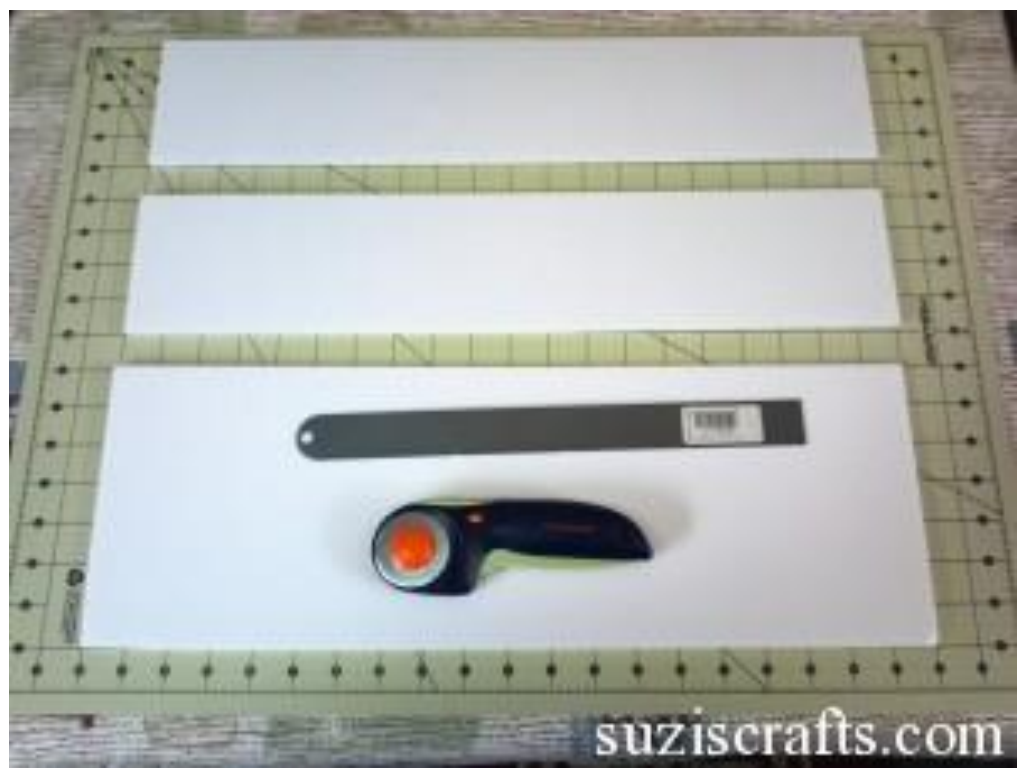

Figure 40: Pieces of Styrofoam cut for the back and top supports of the light box 


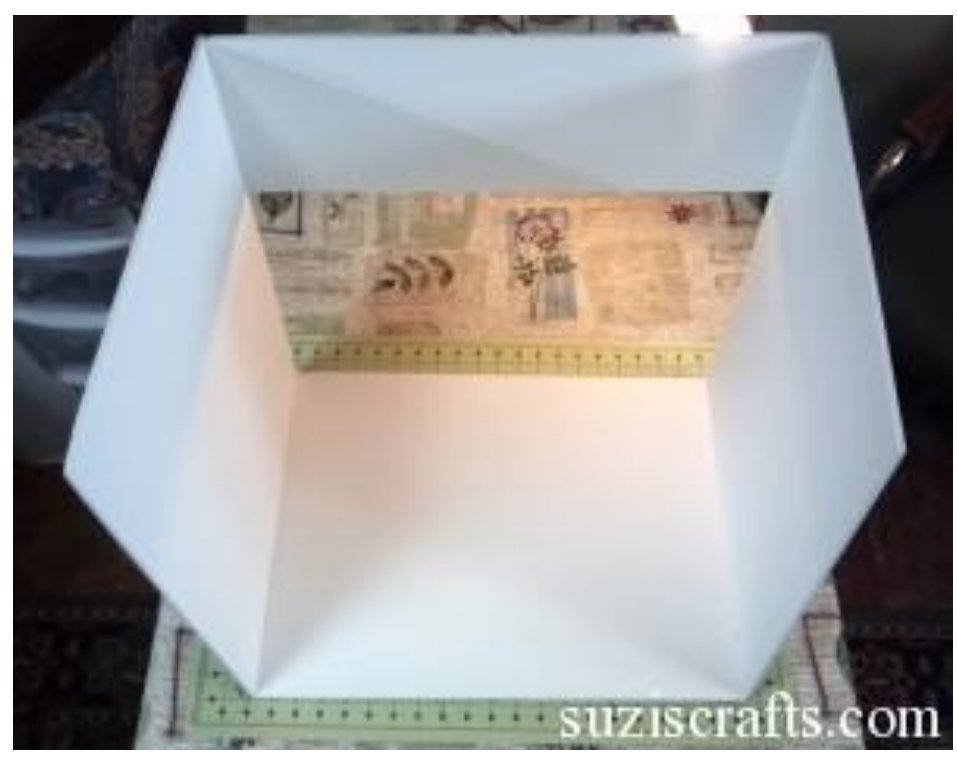

Figure 41: Picture of homemade light box without the top supports or background poster board

As shown below, the background poster board is attached from the front of the bottom to the top of the back with clear tape. I left the top open for the light.

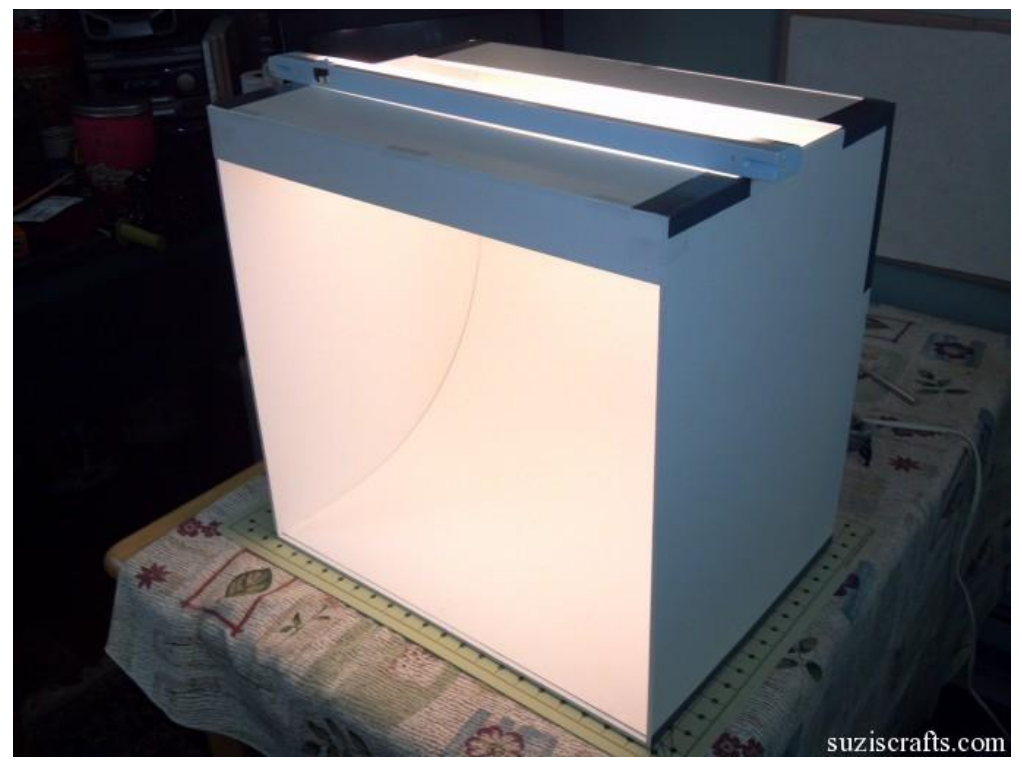

Figure 42: Picture of the homemade light box when completed 
You can use butcher paper over the opening to diffuse the light and even add holes in the side for more light if needed. Turn your flash off and play around with lighting for best results.

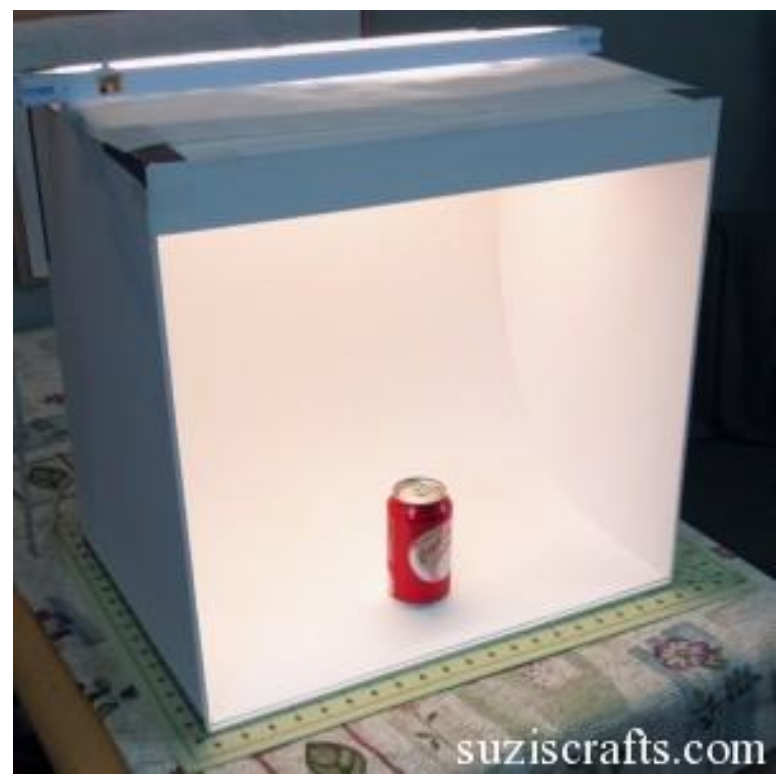

Figure 43: Picture of the homemade light box with example of object placement for photographing

Instructions found at Suzi's Crafts, $\underline{w w w . s u z i s c r a f t s . c o m}$

Light boxes are useful for clean photographs of artwork, specifically 3dimensional artwork. 2-dimensional artwork can be photographed against a large sheet of paper or clean sheet pinned onto a bulletin board. The color choice can vary depending on what color with make your student's work pop out. 2-dimensional art can also be placed on an easel. This light box has its size limitations but another light box can always be constructed to meet your photographic needs. 


\section{Appendix E}

\section{Cover Letter}

WestVirginiaUniversity.

COUEGE OF CREATVE ARTS

Hancock County Schools

PO Box 1300

New Cumberland, WV 26047

Dear Participants:

Thank you signing up for this research project. This study has been reviewed and acknowledged by the IRB of West Virginia University. This project is to fulfill the Master's Thesis requirements of Elissa Dray under the supervision of Dr. Ronald Aman for the West Virginia University Art Department and to research the use of online art galleries by teachers. The purpose of the study is to get an insight into why teachers may not be using online art galleries and how the online art galleries (specifically Artsonia) function.

All responses to questions will be kept anonymous and confidential. Participants will not need to give names or indications of who they may be. Participants will not be videotaped or audio-taped. Participants will not be tested. Participants do not have to answer every question. Class grades or job status will not be affected by the refusal to participate or withdrawal from the study.

At the conclusion of the study digital cameras, provided by the Hancock County Department of Technology will be given away at random. Participation in the study is completely voluntary. Once again, thank you for your participation.

Sincerely,

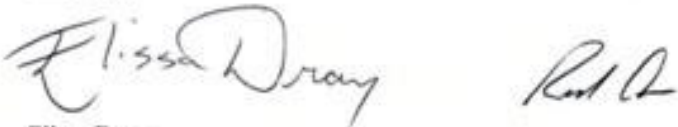

Elissa Dray

Fine Arts

Oak Glen High School

hdray@access.k12.wv.us

Dr. Ronald Aman

Art Education Professor/Principle Investigator

West Virginia University

Ronald.Aman@mail.wvu.edu 


\title{
Appendix F
}

\section{Participant Consent Form}

\section{WestViriniaianiversity.}

Human Research Protocol

Only Minimal Risk Consent Form

Without HIPAA

\author{
Only Minimal Risk \\ Consent Information Form (without HIPAA) \\ Principal Investigator \\ Dr. Ronald Aman \\ Department \\ College of Creative Arts, Art Education \\ Protocol Number \\ 1312151309 \\ Study Title \\ Using Artsonia: Instructing teachers on how to display their student's artwork \\ online \\ Co-Investigator(s) \\ Dr. Victoria Fergus, Elissa Dray \\ Sponsor (if any) \\ Hancock County Board of Education
}

\section{Contact Persons}

In the event you experience any side effects or injury related to this research, you should contact Dr. Aman at (304) 2932051 or the Hancock County School Board Office at (304) 564- 3411. If you have any questions, concerns, or complaints about this research, you can contact Dr. Aman at (304) 293- 2051 or Elissa Dray at (304) 794-6768.

For information regarding your rights as a research subject, to discuss problems, concerns, or suggestions related to the research, to obtain information or offer input about the research, contact the Office of Research Integrity \& Compliance at (304) 293-7073.

In addition if you would like to discuss problems, concerns, have suggestions related to research, or would like to offer input about the research, contact the Office of Research Integrity and Compliance at 304-293-7073.

\section{Introduction}

You, Hancock County Educator, have been asked to participate in this research study, which has been explained to you by Elissa Dray. This study is being conducted by Elissa Dray in the Department of Art Education at West Virginia University with funding sponsored by the Hancock County Board of Education.

\section{Purpose(s) of the Study}

The purpose of the study is to get an insight into why teachers may not be using online art galleries and how the online art galleries (specifically Artsonia) function.

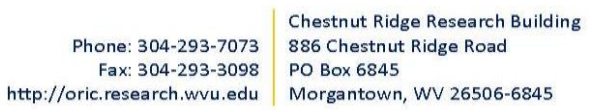

Subject's Initials Date 


\section{Description of Procedures}

This study involves learning about online art galleries and using technological equipment and will take approximately two hours and fifteen minutes for you to complete. You will be asked to fill out a questionnaire regarding online art galleries, displaying projects, and technological equipment. This will take approximately five minutes. You do not have to answer all the questions. You will have the opportunity to see the questionnaire before signing this consent form.

\section{Discomforts}

There are no known or expected risks from participating in this study, except for the mild frustration associated with answering the questions.

\section{Alternatives}

You do not have to participate in this study.

\section{Benefits}

The knowledge gained from this study may eventually benefit others. Benefits to you include: knowledge about a new way to display your student's projects, tips on photography your student's projects, access to thousands of lesson plans, and an alternative method to fundraise for your school.

\section{Financial Considerations}

There are no special fees for participating in this study. At the conclusion of the study, a digital camera or cameras will be given away. Unless the study is confidential, the WVU consent form must inform subjects that they will be asked to provide their Social Security Number and verification of U.S Citizenship or Permanent Resident Status to receive payment. For confidential studies only name and address are required.]

\section{Confidentiality}

Any information about you that is obtained as a result of your participation in this research will be kept as confidential as legally possible. Your research records and test results, just like hospital records, may be subpoenaed by court order or may be inspected by the study sponsor or federal regulatory authorities (including the FDA if applicable) without your additional consent.

In any publications that result from this research, neither your name nor any information from which you might be identified will be published without your consent.

\section{Voluntary Participation}

Participation in this study is voluntary. You are free to withdraw your consent to participate in this study at any time.

Refusal to participate or withdrawal will not affect and will involve no penalty to you. Refusal to participate or withdrawal will not affect your future care, or your employee status at West Virginia University.

\begin{tabular}{|c|c|c|c|}
\hline & Chestn ut Ridge Research Build ing & & Pag e 12 \\
\hline Phone: 304-293-7073 & 886 Chestnut Ridge Road & & \\
\hline Fax: 304-293-3098 & PO Box 6845 & Subject's Initials & \\
\hline http://oric, research.wvu.edu & Morgantown, WV 26506-6845 & Date & \\
\hline
\end{tabular}

Approved:25-Mar-2014Expires:24-Mar-2015Number:1312151309 


\section{W- WestVirginiaUniversity.}

Human Research Protocol Only Minimal Risk Consent Form

Without HIPAA

In the event new information becomes available that may affect your willingness to participate in this study, this information will be given to you so that you can make an informed decision about whether or not to continue your participation.

You have been given the opportunity to ask questions about the research, and you have received answers concerning areas you did not understand.

Upon signing this form, you will receive a copy.

I willingly consent to participate in this research.

Signatures

Signature of Subject

\begin{tabular}{lll}
\hline Printed Name & Date & Time
\end{tabular}

The participant has had the opportunity to have questions addressed. The participant willingly agrees to be in the study.

Signature of Investigator or Co-Investigator

\begin{tabular}{lll}
\hline Printed Name & Date & Time
\end{tabular}

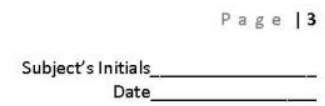

Date

Approved:25-Mar-2014Expires:24-Mar-2015Number:1312151309 


\section{Appendix G}

\section{IRB Approval}

\section{WestVhriginiaUniversity. \\ Office of Research Integrity and Compliance}

\begin{tabular}{ll} 
To & \multicolumn{1}{c}{ Approval Letter Expedited } \\
From & Ronald Aman \\
Approval Period & WVU Office of Research Integrity and Compliance \\
Subject & $03 / 25 / 2014$ Expiration Date $03 / 24 / 2015$ \\
Protocol Tracking & Protocol Approval Letter \\
Title & $\begin{array}{l}1312151309 \\
\text { Using Artsonia: Instructing teachers on how to display their student's artwork } \\
\text { online. }\end{array}$
\end{tabular}

The above-referenced research study was reviewed by the West Virginia University Institutional Review Board IRB and was approved in accordance with 46 CFR 46.101b.

It has been determined that this study is of minimal risk and meets the criteria as defined by the expedited categorys listed below:

- Category 7. Research on individual or group characteristics or behavior (including, but not limited to, research on perception, cognition, motivation, identity, language, communication, cultural beliefs or practices, and social behavior) or research employing survey, interview, oral history, focus group, program evaluation, human factors evaluation, or quality assurance methodologies. [NOTE: Some research in this category may be exempt from the DHHS regulations for the protection of human subjects. See Exempt Categories and 45 CFR $46.101(\mathrm{~b})(2)$ and (b)(3). This listing refers only to research that is not exempt.]

Documents for use in this study have been approved and validated and are available in the WVUkc system in the Notes and Attachments section of your protocol.

Thank you.

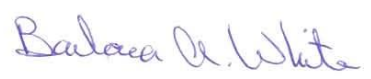

Board Designee Barbara White

Letter Sent By Barbara White on 03/25/2014 at 11:16:44-04:00 
Once you begin your human subject research, the following regulations apply:

1. Unanticipated or serious adverse events/side effects encountered in this research study must be reported to the IRB within five (5) days.

2. Any modifications to the study protocol or informed consent form must be reviewed and approved by the IRB prior to implementation.

3. You may not use a modified informed consent form until it has been approved and validated by the IRB. 